\title{
Effect of bipropellant combustion products on the rocket nozzle design
}

Omar Abada*, Abderahim Abada, and Ahmed Abdallah El-Hirtsi

Aeronautical Sciences Laboratory, Institute of Aeronautics and Space Studies, University of Blida 1, BP 270 Blida 09000, Algeria

Received: 8 June 2019 / Accepted: 4 July 2020

\begin{abstract}
The focus of this research work is to investigate numerically the effect of adding the gas on the design and performance of axisymmetric $M L N$ nozzles. A FORTRAN code was developed to design this nozzle using the characteristics method $(M O C)$ at high temperature. The thermochemical and combustion studies of the most used liquid propellants on the satellites and launch vehicles allow to known all gases. Four engines are investigated: Ariane 5 (Vulcain 2), Ariane-5 upper stage engine (Aestus), Zenit first stage (RD-170) and Falcon 9 upper stage (Raptor). Thermodynamic analysis of parameters design $M L N$ (such as length, Mach number, mass, thrust coefficient) was conducted. The comparison shows that the presence of $50 \%$ of $\mathrm{H}_{2} \mathrm{O}$ gas in combustion species increases the nozzle design parameters (diatomic gas including air) in the order of $25 \%$. On the other hand, the existence of $\mathrm{CO}_{2}$ gas considerably increases approximately $35 \%$ the length and the exhaust radius. These rise depend on gases percentage in the combustion. The truncation method is applied in the $M L N$ nozzles to optimize the thrust/weight ratio.
\end{abstract}

Keywords: Minimum length nozzle / high temperature / calorically imperfect gas / method of characteristics / numerical simulation

\section{Introduction}

The spacecraft performance optimization design can be improved by thermodynamics and aerodynamics studies, for example, minimizing the pressure and friction losses for internal and external flows may increase the vehicle range and payload. For this purpose, the propulsion systems are used to correct and maintain the satellite at its nominal position. Generally, a propulsion system is a system that accelerates a material to provide a thrust force that moves a vehicle or rotates it relative to its centre of mass. The nozzle is one of the most important components of this engine because its efficiency greatly affects the performance of the engine [1]. By minimizing the losses in the nozzle, the rocket's thrust will be increased.

Rao has developed a method that optimizes a rocket nozzle contour for a given length or expansion ratio so that the maximum thrust is reached. In a study by [2,3], three large optimized Rao steeple nozzles have been compared to a 15-degree conical nozzle. The thrust produced by the optimized nozzles is considerably greater than that obtained with the conical nozzle. In this study, the choice is based on a type called axisymmetric minimum length

\footnotetext{
* e-mail: abadaomar@ymail.com
}

nozzle, which gives a uniform flow and parallel to the exit section [4-6]. All previous studies were based on using a perfect gas model $(P G)$, in which the specific heat $C_{P}$ and $\gamma$ are constant and do not depend on temperature. In reality these parameters vary with temperature [7-9] have developed a mathematical model that takes account of this temperature. The new model is called the model of perfect gas at high temperature $(H T)$. In this context, the mathematical model of the perfect gas $(P G)$ becomes a special case of the model with high temperature $(H T)$. The design of nozzles operating with non-ideal gases is currently an active area of research in the design of ORC turbines [10-12].

The thrust of a propulsive system primarily depends on the amount of combustion products ejected through it [1]. So, considering air for the design of supersonic nozzles is far from reality [13]. The use of gas other than air influences essentially the behaviour of supersonic flows and in particular the physical thermodynamic $\left(P / P_{0}, T / T_{0}\right.$, $\left.\rho / \rho_{0},\right)$ and geometric parameters $\left(A / A^{*}, C_{F}, M a s s\right)$ of the nozzle design [14]. In this reference, the author did not clearly show the influence of the addition of the concentrations of the gases resulting from a combustion on the design of the nozzles. It is clear that these gases come from a combustion of bipropellants (oxidizer/fuel). For this reason, a use of the thermochemical study of the combustion 
of the most used and popular liquid propellants on engines (launchers and satellites) provided us the necessary information for the equilibrium composition at assumed temperature. Four engines were studied: the main stage of the Ariane- 5 (Vulcain 2), the second stage of the Ariane-5 launcher (Aestus), the first stage of the Zenit launcher (RD-170) and the upper stage Falcon 9 (Raptor). These engines respectively use the following liquid propellants: hydrogen/oxygen, monomethyl hydrazine/Nitrogen tetroxide, kerosene/oxygen and methane/oxygen. Edwards [15] and Amri et al., [16] carried out a study of the chemical reactions of these four engines. The gases types resulting from the combustion are: triatomic $\left(\mathrm{H}_{2} \mathrm{O}, \mathrm{CO}_{2}\right)$, diatomic $\left(\mathrm{H}_{2}, \mathrm{OH}, \mathrm{CO}, \mathrm{O}_{2}\right.$, and $\left.\mathrm{N}_{2}\right)$ and monoatomic $(\mathrm{O}, \mathrm{H}, \mathrm{N})$.

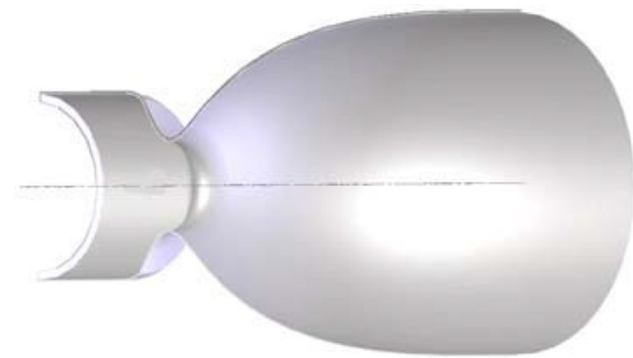

Fig. 1. Presentation of the axisymmetric $M L N$ nozzle.

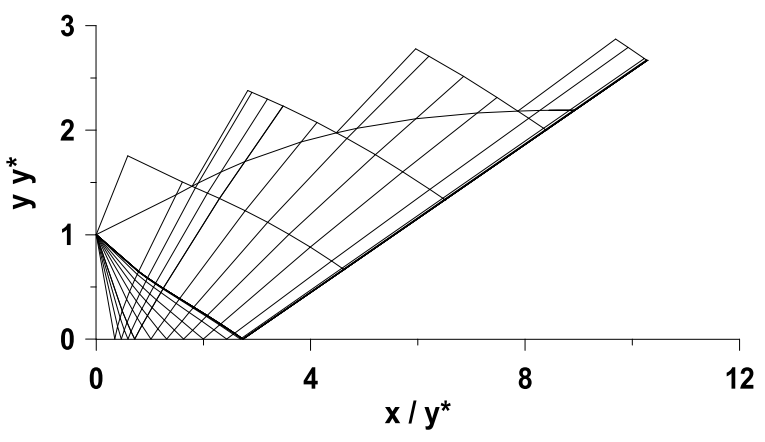

(a)

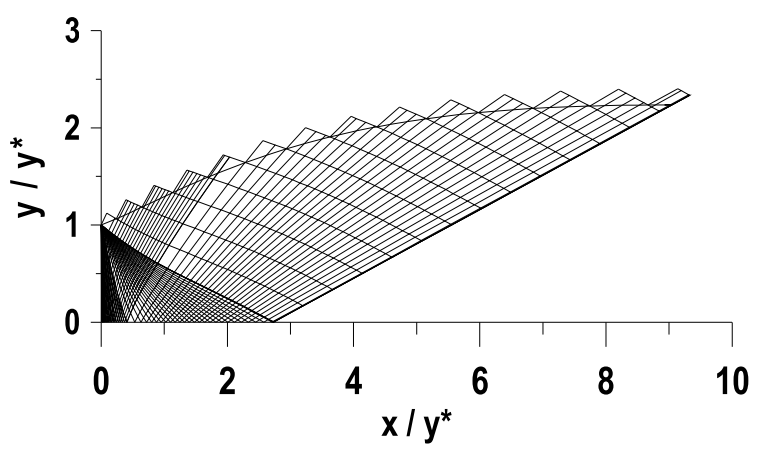

(c)
The aim of the present paper is to develop a numerical program for studying the effect of these gases triatomic and diatomic on the performance of the axisymmetric $M L N$ supersonic nozzles, using the length, the exit Mach number, the mass and the thrust coefficient parameters.

\section{Design method of the axisymmetric MLN nozzle (Case of Air)}

In this study, a nozzle type which gives a uniform flow and parallel to the exit section is chosen. It is named minimum length nozzle $(M L N)$ with centered expansion. This type of nozzle has a minimum length compared to other existing types [17]. Figure 1 illustrates the general diagram of the axisymmetric nozzle of minimum length with straight sonic line

The method of characteristics (MOC) at high temperature is undertaken to perform the nozzle design in order to:

- Find the nozzle's contour for a given exit Mach number $M_{E}$.

- Calculate the internal flow field in the axisymmetric $M L N$.

The relations (1) and (2) below represent the characteristics equations and compatibilities for a supersonic, irrotational, adiabatic flow of a perfect gas [17-19] and are respectively valid on the $\mathrm{C}^{-}$and $\mathrm{C}^{+}$characteristics as shown in Figure 2.

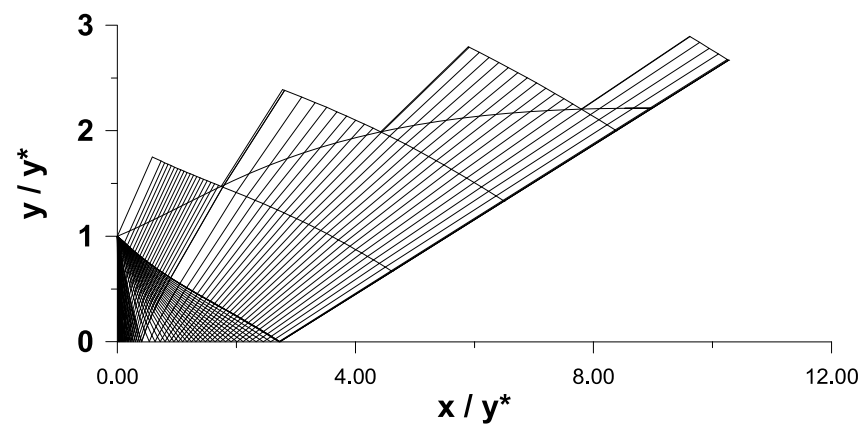

(b)

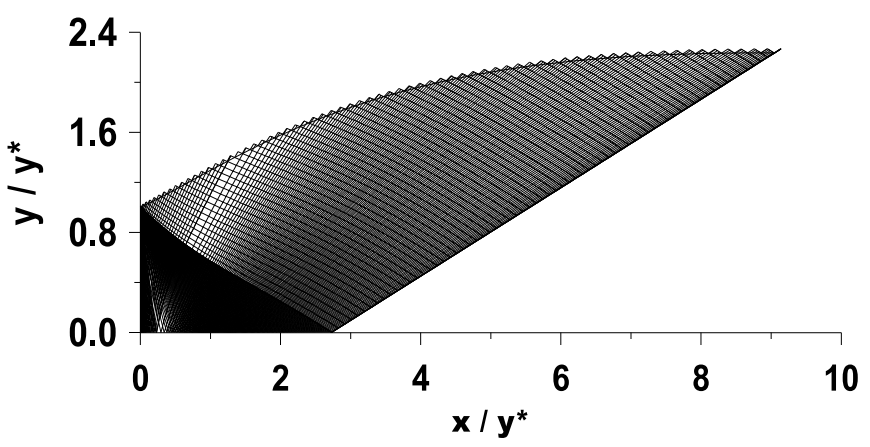

(d)

Fig. 2. Contour nozzle and mesh of the nozzle for $M_{E}=3.00$ and $T_{0}=2000 \mathrm{~K}$. (a) Large grid. (b) Moderate grid. (c) Rather fine grid. (d) Fine grid. 


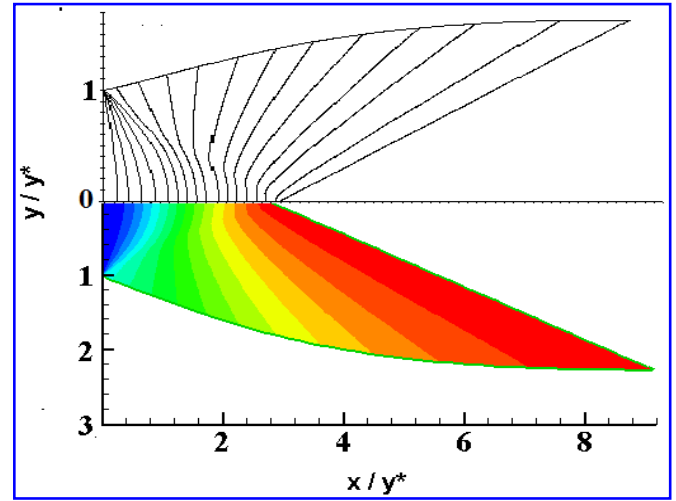

(a)

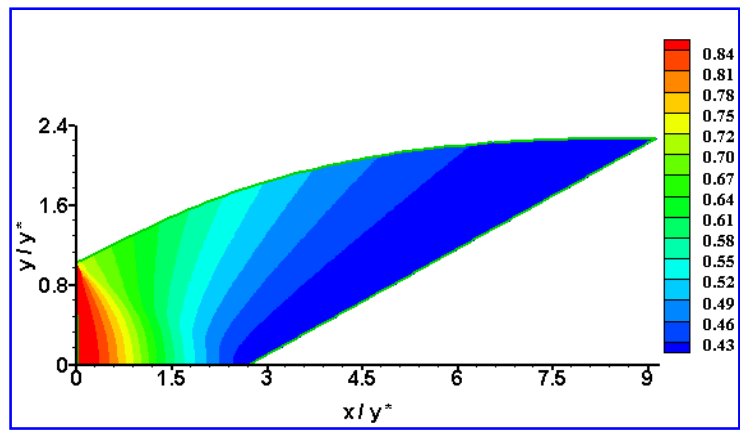

(c)

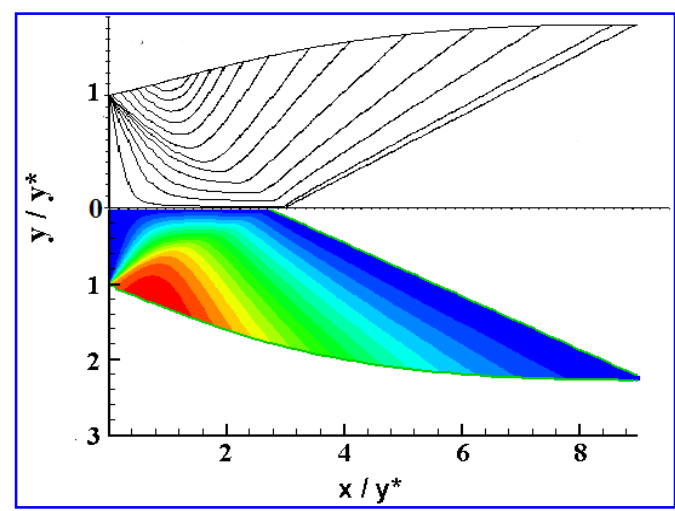

(b)

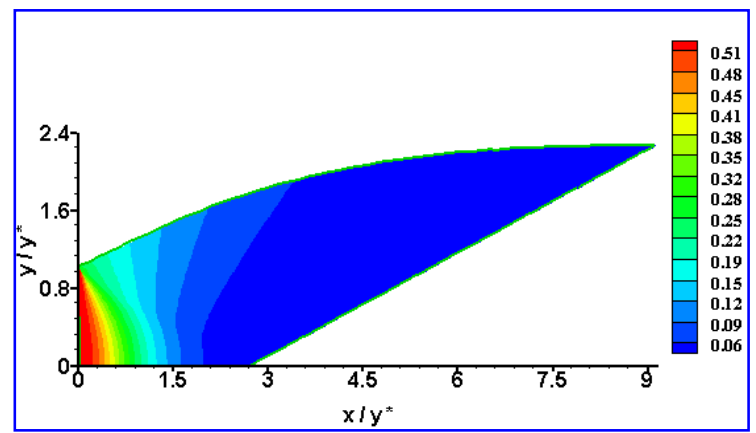

(d)

Fig. 3. Numerical results of the flow of air in an axisymmetric nozzle $M L N$ for $M_{E} 3.00$ and $T_{0}=2000 \mathrm{~K}$. (a) Iso-Mach curves (Ref. [19] and numerical results). (b) Iso-Directions curves (Ref. [19] and numerical results). (c) Iso-temperatures ratio ( $\left.T / T_{0}\right)$ curves. (d) Iso-Pressures ratio $\left(P / P_{0}\right)$ curves.

Following $\xi \underline{(1-3)}$ :

$$
\left\{\begin{array}{l}
d(v+\theta)=\frac{\sin \theta \sin \mu}{y} d \xi \\
\frac{\mathrm{d} y}{\mathrm{~d} x}=\operatorname{tg}(\theta-\mu)
\end{array}\right.
$$

Following $\eta \underline{(2-3)}$ :

$$
\left\{\begin{array}{l}
d(v-\theta)=\frac{\sin \theta \sin \mu}{y} d \eta \\
\frac{\mathrm{d} y}{\mathrm{~d} x}=\operatorname{tg}(\theta+\mu)
\end{array}\right.
$$

where $v$ is the Prandtl Meyer function at high temperature (HT) [19].

The use of the method of the characteristics $(M O C)$ let us to introduce a fine mesh in order to approximate each characteristic between two points by straight line segments. The properties $(x, y, T, \theta, \rho, P)$ at a flow field point can be determined from two points connected with a point considered by the characteristic lines that comes before it. Therefore, thermodynamic parameters have been calculated for each point of the mesh, as well as the performance parameters of the axisymmetric nozzle $M L N$. The calculation of the flow in the nozzle is divided into two regions named as Kernel and transition regions. The numerical results obtained between the radius of the numerically calculated exit section and the ratio of the standard theoretical sections $\left(y^{*}=1.0\right)$ presented by the following formula will be compared.

Figure 2 illustrates a result of the numerical code which represents a mesh and contour design at high temperature axisymmetric nozzle $(M L N)$ for exit Mach number $M_{E}=3.00$ and $T_{0}=2000 \mathrm{~K}$. This applies for air.

Figure 3 gives the fluid's parameters results obtained numerically for an axisymmetric $M L N$ nozzle for Mach $M_{E}=3.00$ and $T_{0}=2000 \mathrm{~K}$. It is clear to note that the isoMach contour and the iso-values match those of the references [19].

After obtaining the flow at all points of the flow field in the axisymmetric $M L N$, we can proceed to the study of the thermodynamics parameter evolution (Mach, flow angle deviation, pressure, temperature and density) on the wall of the nozzle (see Fig. 4). To do this, a three-dimensional mesh of the nozzle contour is realized by applying the definition of the streamlines in space. A refinement of the contour is necessary by refining of the number of 


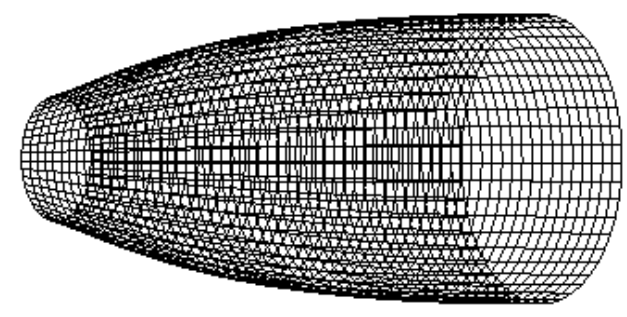

Fig. 4. Thee-dimensional mesh of the axisymmetric $M L N$ contour for $T_{0}=2000 \mathrm{~K}$ and $M_{E}=3.00$.

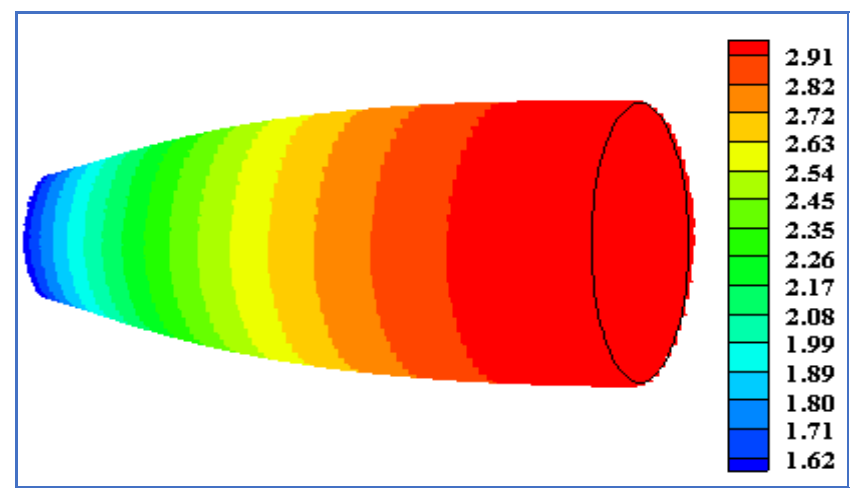

Fig. 5. Variation of $M$ along the wall.

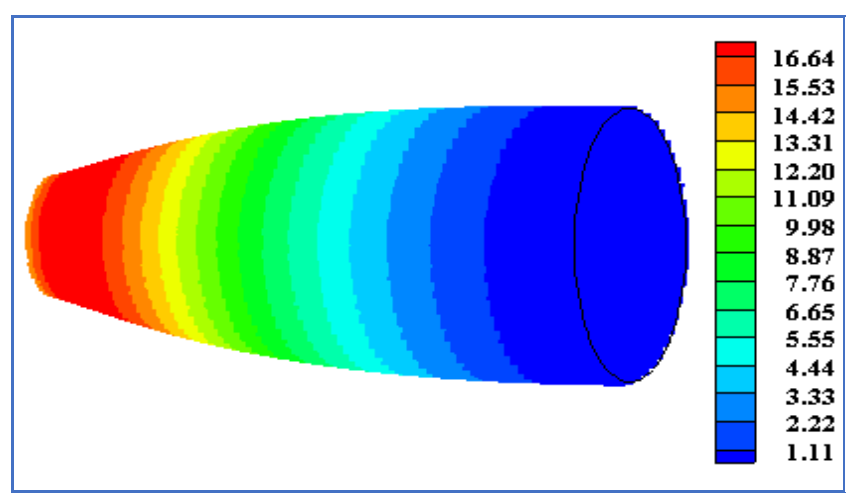

Fig. 6. Variation of $\theta^{*}$ along the wall.

longitudinal sections $N_{L}$ and transversely points $N_{T}[17,18]$. Figures 5-9 show the results obtained by our calculation program.

\section{Study of combustion for bipropellants}

The objectives here are to determine the theoretical combustion temperature and the theoretical composition of the resulting reaction products. The first principle concerns the conservation of energy. The heat created by the combustion is equal to the heat necessary to raise the resulting gases adiabatically to their final combustion

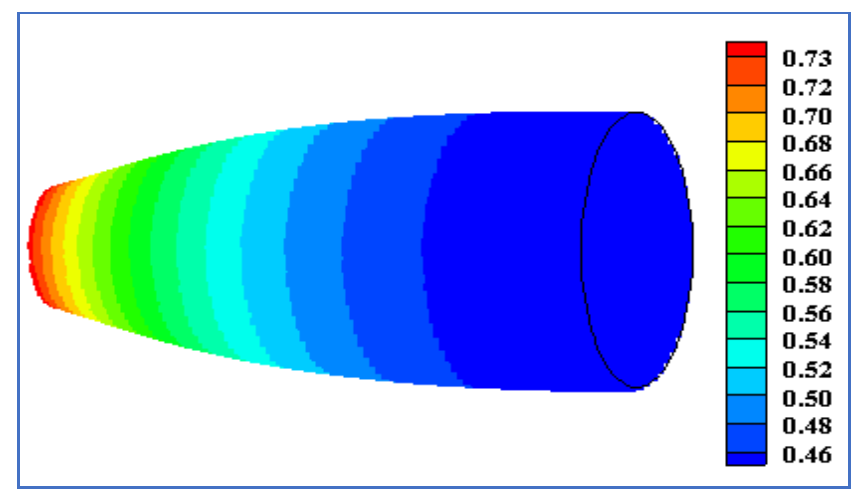

Fig. 7. Variation of $T / T_{0}$ along the wall.

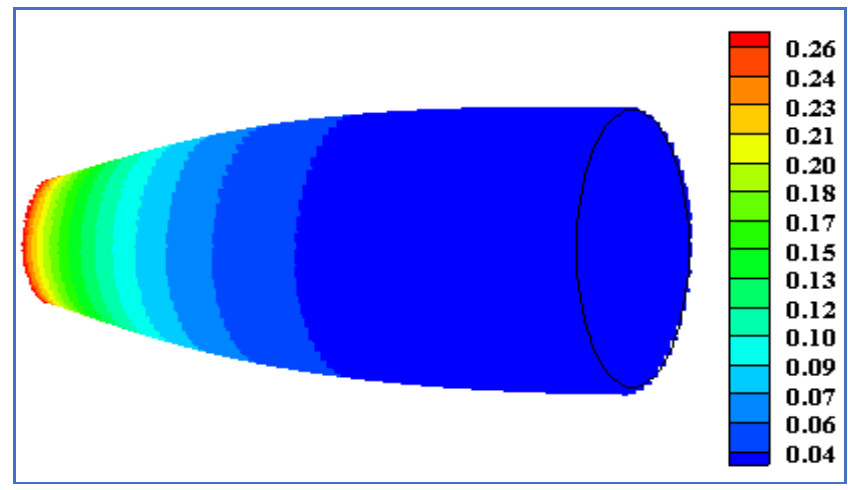

Fig. 8. Variation of $P / P_{0}$ along the wall.

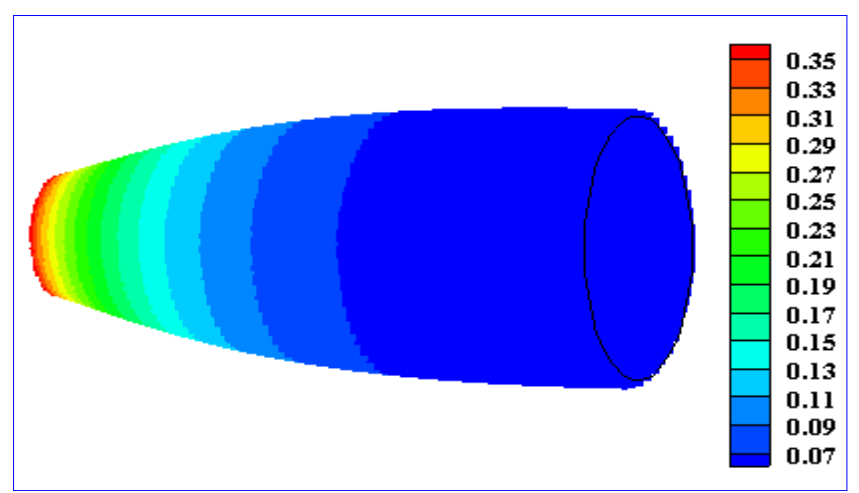

Fig. 9. Variation of $\rho / \rho_{0}$ along the wall.

temperature. The heat of reaction of the combustion $\Delta H_{r}$ has to equal the enthalpy change $\Delta H$ of the gases.

$$
\Delta H_{r}=\sum_{1}^{n} n_{j} \int_{T_{r e f}}^{T_{1}} C_{P} d T=\left.\sum_{1}^{n} n_{j} \Delta h_{j}\right|_{T_{r e f}} ^{T_{1}}
$$

where $\Delta H_{r}$ the energy difference between the reactants and products under standard conditions $(\mathrm{kJ})$.

The second principle is the conservation of mass. The mass of any of the atomic species present in the reactants before the chemical reaction must be equal to the mass of the same species in the products. The combustion of the following propellant combinations was studied: 


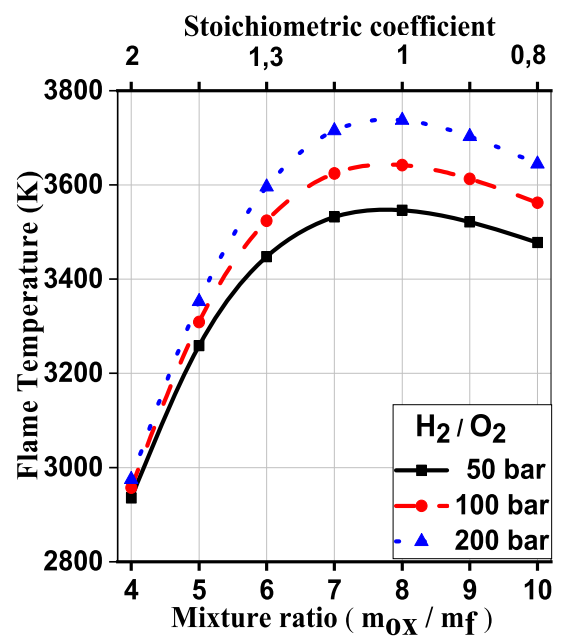

Fig. 10. Pressure effect on the flame temperature of the combustion $\mathrm{H}_{2} / \mathrm{O}_{2}$.

hydrogen/oxygen, hydrocarbon fuel/oxygen, hydrocarbon fuel/hydrogen peroxide, hydrazine/nitrogen tetroxide and mono-methyl hydrazine/Nitrogen tetroxide. The following five (05) chemical reactions were considered:

- Liquid hydrogen $\left(\mathrm{H}_{2}\right)$ and liquid oxygen $\left(\mathrm{O}_{2}\right)$

$$
\begin{aligned}
2 \alpha \mathrm{H}_{2}+\mathrm{O}_{2} \rightarrow & \mathrm{n}_{\mathrm{H}_{2} \mathrm{O}} \mathrm{H}_{2} \mathrm{O}+\mathrm{n}_{\mathrm{H}_{2}} \mathrm{H}_{2}+\mathrm{n}_{\mathrm{O}_{2}} \mathrm{O}_{2} \\
& +\mathrm{n}_{\mathrm{O}} \mathrm{O}+\mathrm{n}_{\mathrm{H}} \mathrm{H}+\mathrm{n}_{\mathrm{OH}} \mathrm{OH}
\end{aligned}
$$

- Hydrocarbon fuel $\left(\mathrm{C}_{\mathrm{n}} \mathrm{H}_{\mathrm{m}}\right)$ and liquid oxygen $\left(\mathrm{O}_{2}\right)$

$$
\begin{aligned}
\alpha \mathrm{C}_{\mathrm{n}} \mathrm{H}_{\mathrm{m}}+\mathrm{O}_{2} \rightarrow & \mathrm{n}_{\mathrm{CO}_{2}} \mathrm{CO}_{2}+\mathrm{n}_{\mathrm{H}_{2} \mathrm{O}} \mathrm{H}_{2} \mathrm{O}+\mathrm{n}_{\mathrm{O}_{2}} \mathrm{O}_{2} \\
& +\mathrm{n}_{\mathrm{CO}} \mathrm{CO}++\mathrm{n}_{\mathrm{OH}} \mathrm{OH}+\mathrm{n}_{\mathrm{H}_{2}} \mathrm{H}_{2} \\
& +\mathrm{n}_{\mathrm{O}} \mathrm{O}+\mathrm{n}_{\mathrm{H}} \mathrm{H}
\end{aligned}
$$

- Hydrocarbon fuel $\left(\mathrm{C}_{\mathrm{n}} \mathrm{H}_{\mathrm{m}}\right)$ and hydrogen peroxide $\left(\mathrm{H}_{2} \mathrm{O}_{2}\right)$

$$
\begin{aligned}
\alpha \mathrm{C}_{\mathrm{n}} \mathrm{H}_{\mathrm{m}}+\mathrm{H}_{2} \mathrm{O}_{2} \rightarrow & \mathrm{n}_{\mathrm{CO}_{2}} \mathrm{CO}_{2}+\mathrm{n}_{\mathrm{H}_{2} \mathrm{O}} \mathrm{H}_{2} \mathrm{O}+\mathrm{n}_{\mathrm{O}_{2}} \mathrm{O}_{2} \\
& +\mathrm{n}_{\mathrm{CO}} \mathrm{CO}++\mathrm{n}_{\mathrm{OH}} \mathrm{OH} \\
& +\mathrm{n}_{\mathrm{H}_{2}} \mathrm{H}_{2}+\mathrm{n}_{\mathrm{O}} \mathrm{O}+\mathrm{n}_{\mathrm{H}} \mathrm{H}
\end{aligned}
$$

- Mono-methyl hydrazine (MMH) and nitrogen tetroxide $\left(\mathrm{N}_{2} \mathrm{O}_{4}\right)$

$$
\begin{aligned}
& 4 \alpha \mathrm{CH}_{3}-\mathrm{NH}-\mathrm{NH}_{2}+5 \mathrm{~N}_{2} \mathrm{O}_{4} \\
& \rightarrow \mathrm{n}_{\mathrm{CO}_{2}} \mathrm{CO}_{2}+\mathrm{n}_{\mathrm{H}_{2} \mathrm{O}} \mathrm{H}_{2} \mathrm{O}+\mathrm{n}_{\mathrm{O}_{2}} \mathrm{O}_{2}+\mathrm{n}_{\mathrm{N}_{2}} \mathrm{~N}_{2} \\
& \quad+\mathrm{n}_{\mathrm{NO}} \mathrm{NO}+\mathrm{n}_{\mathrm{CO}} \mathrm{CO}+\mathrm{n}_{\mathrm{OH}} \mathrm{OH}+\mathrm{n}_{\mathrm{H}_{2}} \mathrm{H}_{2} \\
& \quad+\mathrm{n}_{\mathrm{O}} \mathrm{O}+\mathrm{n}_{\mathrm{H}} \mathrm{H}
\end{aligned}
$$

- Hydrazine $\left(\mathrm{N}_{2} \mathrm{H}_{4}\right)$ and nitrogen tetroxide (N2O4)

$$
\begin{aligned}
2 \alpha \mathrm{N}_{2} \mathrm{H}_{4}+\mathrm{N}_{2} \mathrm{O}_{4} \rightarrow & \mathrm{n}_{\mathrm{H}_{2} \mathrm{O}} \mathrm{H}_{2} \mathrm{O}+\mathrm{n}_{\mathrm{O}_{2}} \mathrm{O}_{2}+\mathrm{n}_{\mathrm{N}_{2}} \mathrm{~N}_{2} \\
& +\mathrm{n}_{\mathrm{NO}} \mathrm{NO}+\mathrm{n}_{\mathrm{OH}} \mathrm{OH}+\mathrm{n}_{\mathrm{H}_{2}} \mathrm{H}_{2} \\
& +\mathrm{n}_{\mathrm{O}} \mathrm{O}+\mathrm{n}_{\mathrm{H}} \mathrm{H}
\end{aligned}
$$

It will be noted that at each iteration, the composition of the equilibrium composition of the combustion is

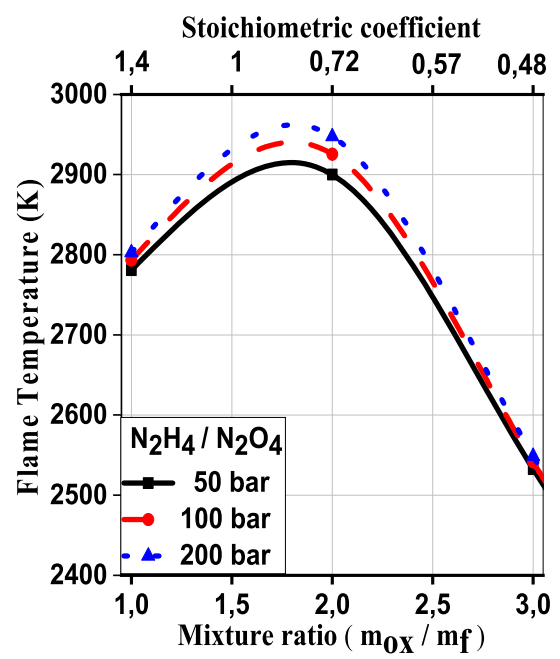

Fig. 11. Pressure effect on the flame temperature of the combustion $\mathrm{N}_{2} \mathrm{H}_{4} / \mathrm{N}_{2} \mathrm{O}_{4}$.

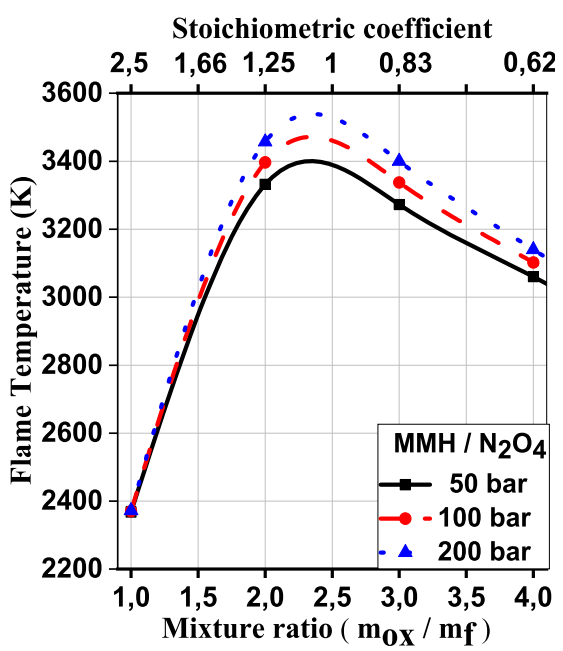

Fig. 12. Pressure effect on the flame temperature of the combustion $\mathrm{MMH} / \mathrm{N}_{2} \mathrm{O}_{4}$.

required at any temperature in the range of [1000, 6000]. To do this, it is necessary to solve the system of nonlinear equations for each equations (4)-(8). The Lieberstein numerical method was used to solve the problem.

Figures 10-15 give the effect of pressure on the flame temperature of the combustion for each liquid propellant when the chamber pressure is 50 bar, 100 bar and 200 bar.

Figures 16-21 show all the obtained results by the realized numerical program for each bipropellant combinations when the chamber pressure is 50 bar, 100 bar and 200 bar.

This study is based on the thermochemical aspect and the combustion of the most used bipropellants combination on launchers and satellites. It is essential to evaluate their performance and provide us with the necessary information during the design of the launcher engine. As an application, four engines were studied in the present paper (Vulcain 2, Aestus, RD-170, Raptor and RD-161P engines). Table 1 shows the input data used for the study. 


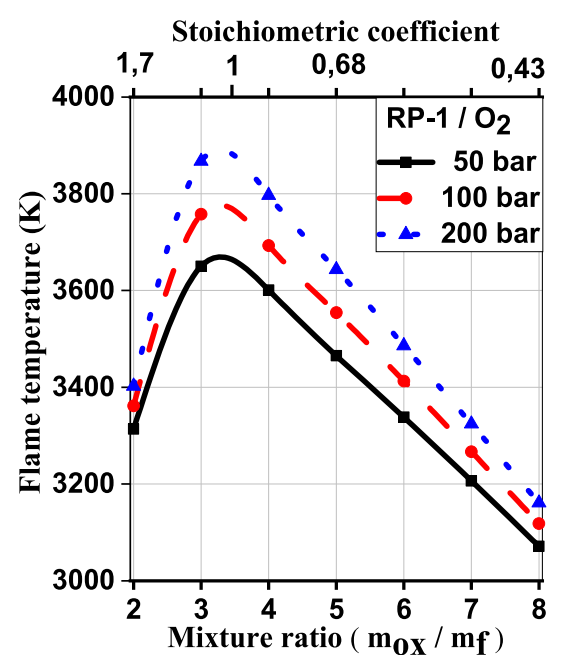

Fig. 13. Pressure effect on the flame temperature of the combustion RP-1/O $\mathrm{O}_{2}$.

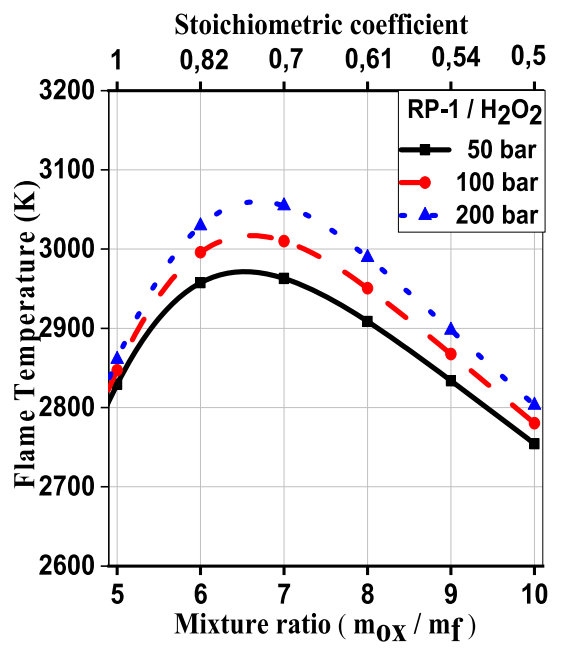

Fig. 14. Pressure Effect on the flame temperature of the combustion RP-1/ $\mathrm{N}_{2} \mathrm{O}_{4}$.

Figure 22 gives the results of the four engines to the combustion products of the bipropellant combinations: hydrogen/oxygen, hydrocarbon fuel/oxygen, Mono-methyl hydrazine/nitrogen tetroxide and Methane/oxygen. The gas produced from different bipropellant combustions are: triatomic, diatomic and monoatomic types.

Table 2 gives the results in term of vacuum specific impulse, flame temperature, molecular mass and politropic parameter.

In order to obtain the nozzles contours of bipropellant engines, the method of characteristics $(M O C)$ at high temperature can be using, provided that the thermodynamic properties of the combustion products (triatomic and diatomic) of the different combustion are known. Particular attention is paid to the variation of the specific heat at constant pressure $C_{P}(T)$ as a function of temperature and to the thermodynamic constant of the gases $\gamma(T)$. Figure 23 illustrates these variations.

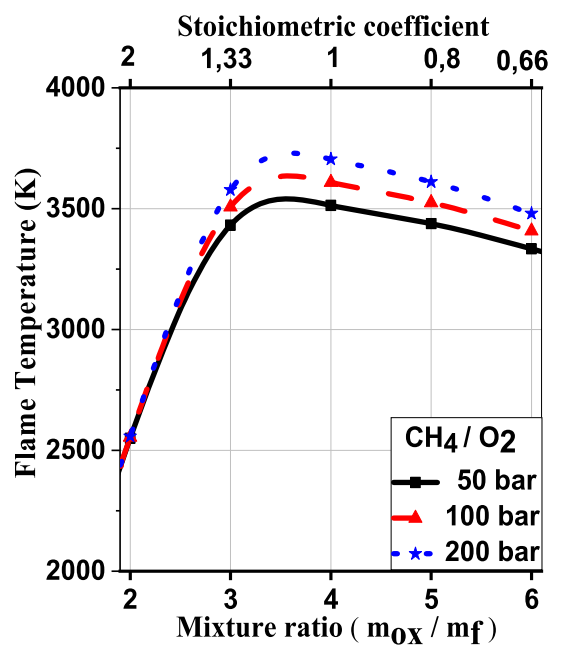

Fig. 15. Pressure effect on the flame temperature of the combustion $\mathrm{CH}_{4} / \mathrm{O}_{2}$.

From Figure 23, we can notice that, contrary to the $\gamma$ ratio, $C_{P}(T)$ of all gases increases with the temperature $T_{0}$. Computational program requires analytical forms for the $C_{P}(T)$ function of each gas. Polynomial interpolations from values of the tables was used [20]. Figure 24 gives the results in term of error for $\mathrm{C}_{\mathrm{PCO} 2}$ with different polynomials interpolations (4th, 5th, 6th, 7th, 8th and 9th degree). The choice was oriented towards polynomial interpolations of 9 th degree.

$$
\begin{array}{r}
C_{P}(T)=\mathrm{a}_{1}+\mathrm{T}\left(\mathrm { a } _ { 2 } \mathrm { T } \left(\mathrm{a}_{3}+\mathrm{T}\left(\mathrm{a}_{4}+\mathrm{T}\left(\mathrm{a}_{5}+\mathrm{T}\left(\mathrm{a}_{6}\right.\right.\right.\right.\right. \\
\left.\left.\left.\left.\left.+\mathrm{T}\left(\mathrm{a}_{7}+\mathrm{T}\left(\mathrm{a}_{8}+\mathrm{T}\left(\mathrm{a}_{9}+\mathrm{T}\left(\mathrm{a}_{10}\right)\right)\right)\right)\right)\right)\right)\right)\right)
\end{array}
$$

where $a_{i}$ are the interpolation coefficients.

Applying the method of characteristics at high temperature $(M O C)$ with the functions of $C_{P}(T)$ for each gas, various results were obtained by computational program and are presented in what follows. Figure 25 shows the shape of the nozzle for the four engines (Vulcain 2, Aestus, RD-170 and Raptor).

In order to clearly illustrate the difference between the design parameters of the various engines, the results obtained as shown in Table 3.

In minimum length nozzles, the last part of the diverging section is substantially constant and therefore it contributes only a few percent to the total thrust. For reasons of optimization, these nozzles must be truncated in order to increase their performance. The latter consists in truncating the nozzle at a welldefined section having almost the same properties as those of the exit section. As an example in practice, the ideal truncated nozzle that equips the Viking engines of the launcher Ariane 4 are cited [21]. Usually, the truncation is performed, at an angle of inclination of the flow $\theta$ equal to 3 degree in general. In this case, the mass of the nozzle is considerably reduced. However, the thrust delivered by the nozzle decreases slightly. Table 4 shows the mass gain and the loss of thrust coefficient calculated by the computation code truncated at $30 \%$. 

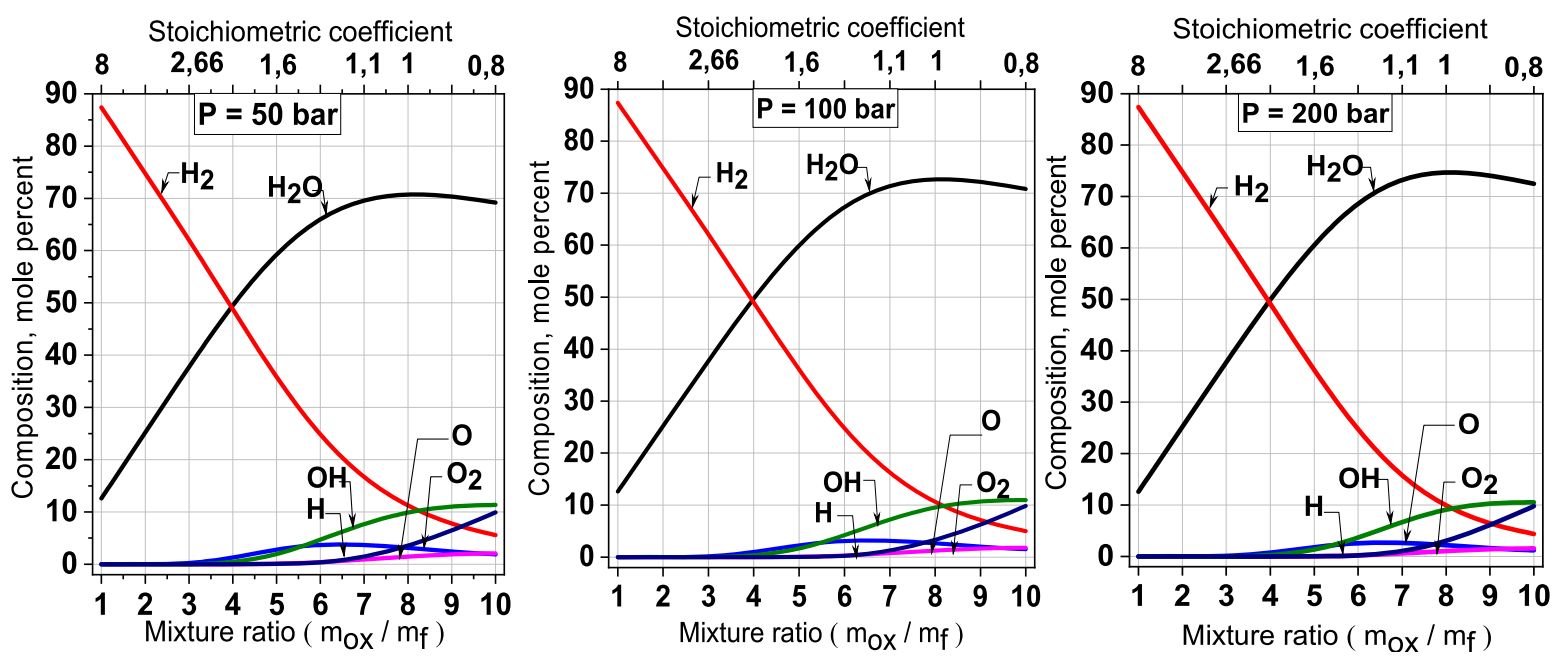

Fig. 16. Combustion products (\%) of the bipropellants $\mathrm{H}_{2} / \mathrm{O}_{2}$.
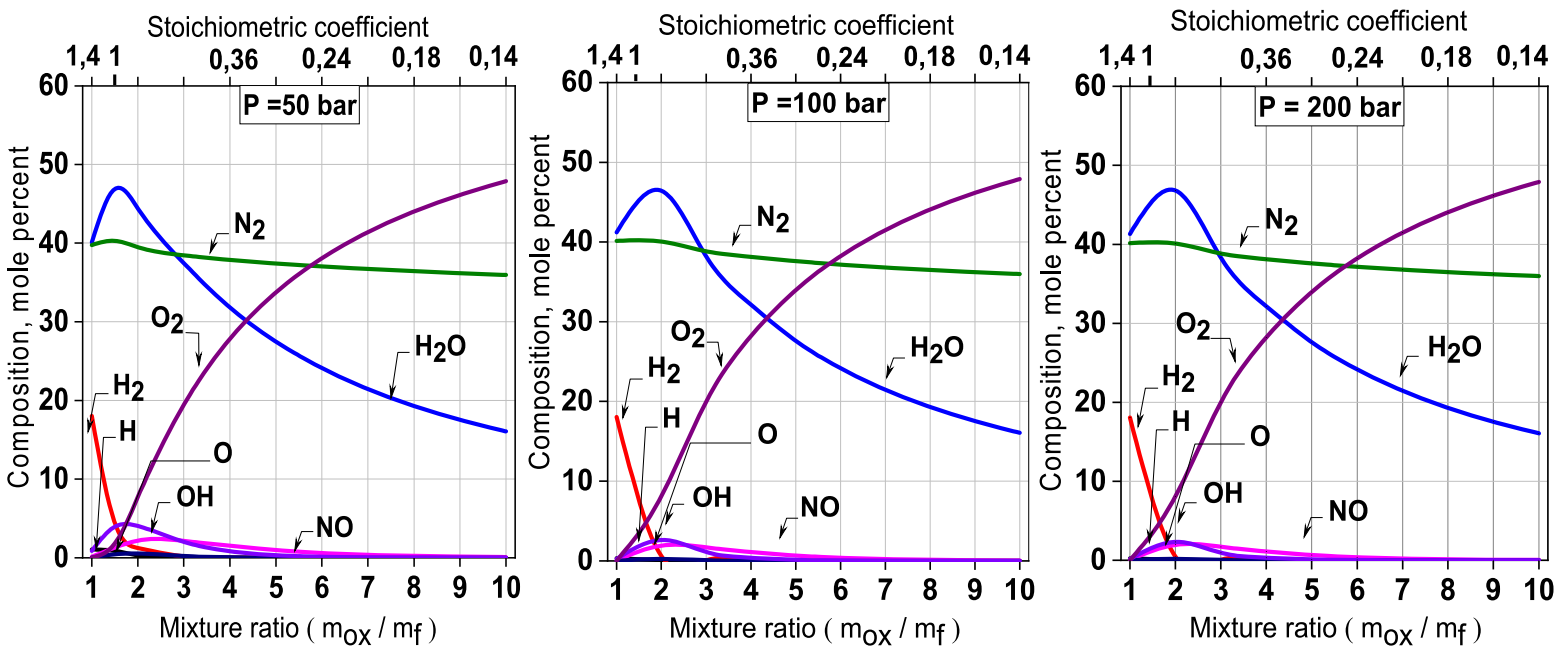

Fig. 17. Combustion products (\%) of the bipropellants $\mathrm{N}_{2} \mathrm{H}_{4} / \mathrm{N}_{2} \mathrm{O}_{4}$.
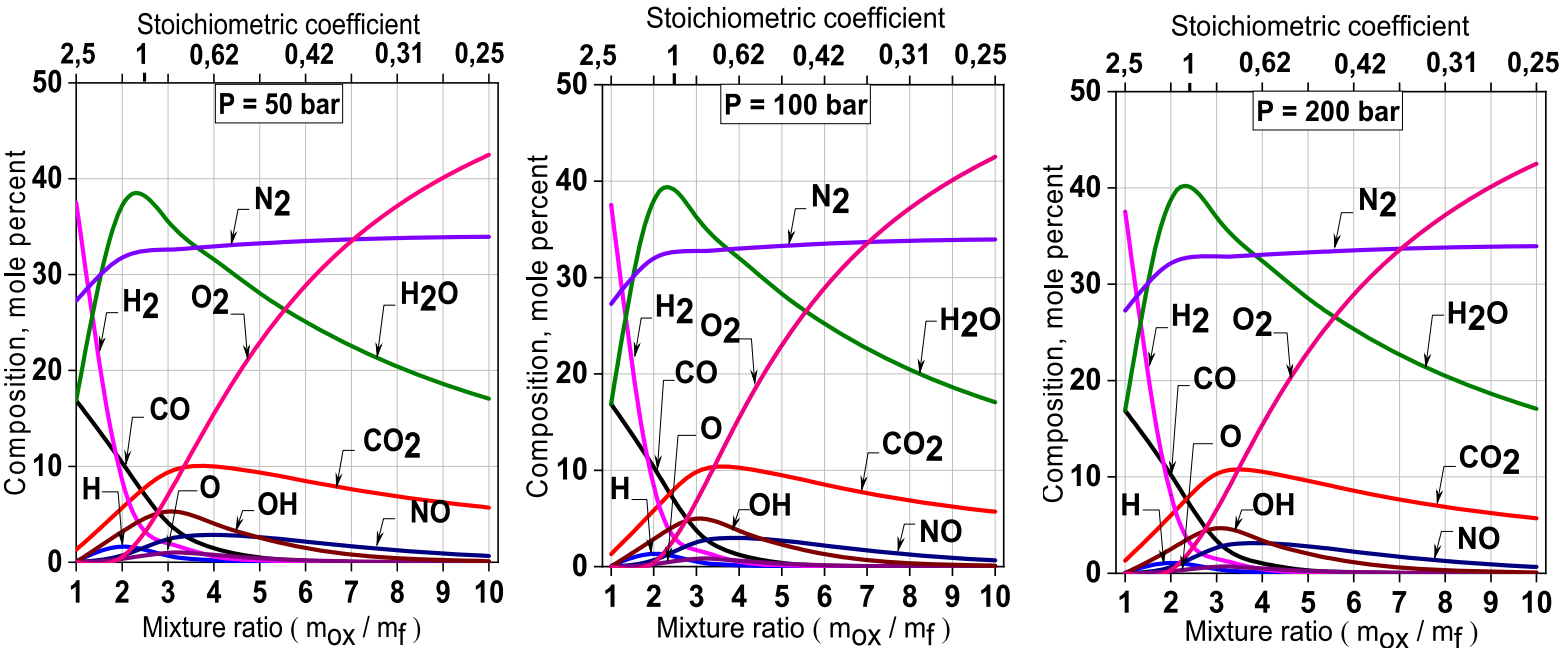

Fig. 18. Combustion products (\%) of the bipropellants $\mathrm{MMH} / \mathrm{N}_{2} \mathrm{O}_{4}$. 

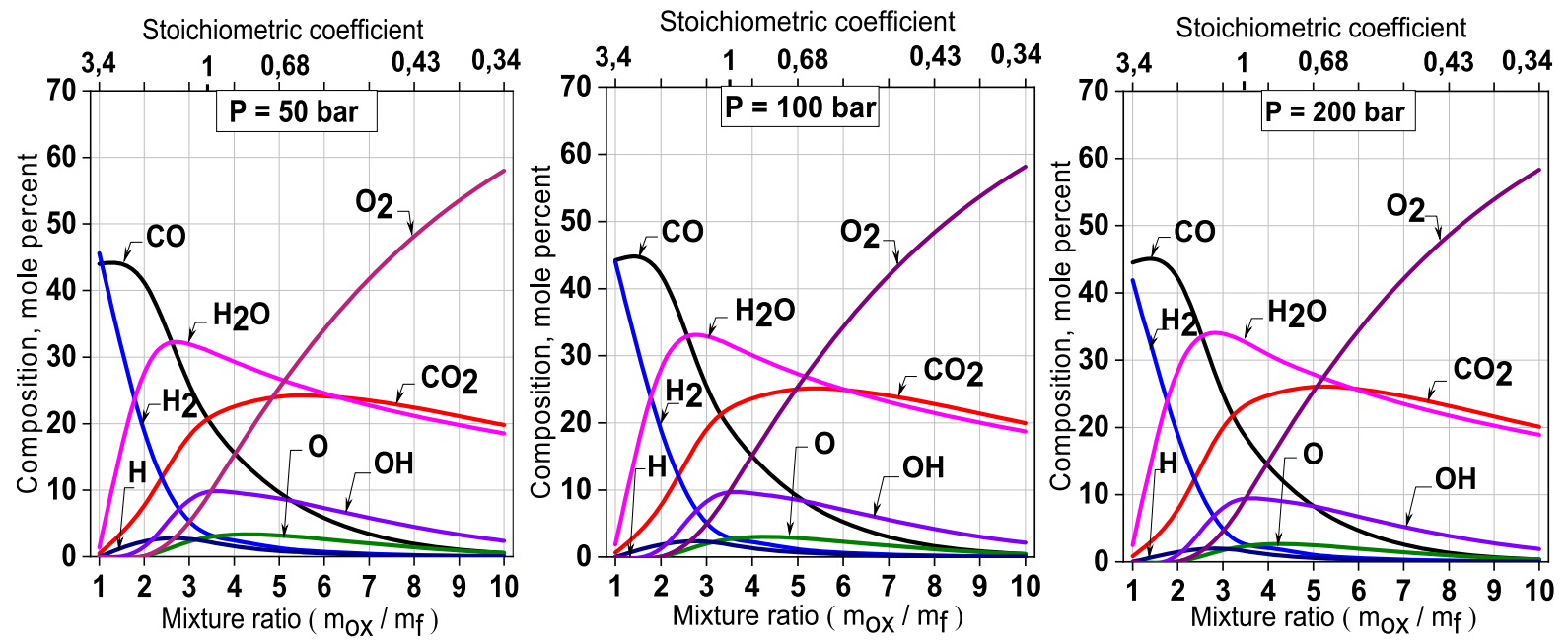

Fig. 19. Combustion products (\%) of the bipropellants $\mathrm{RP}-1 / \mathrm{O}_{2}$.
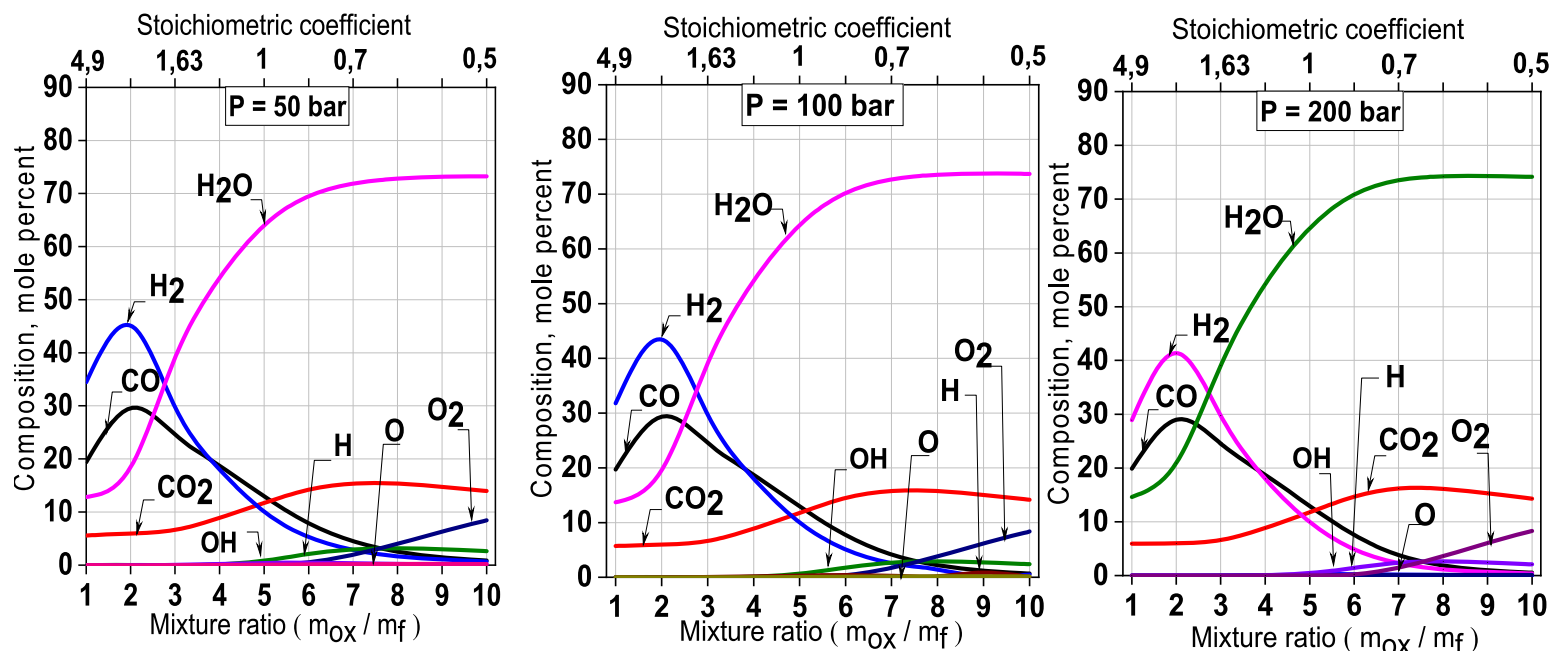

Fig. 20. Combustion products (\%) of the bipropellants $\mathrm{RP}-1 / \mathrm{N}_{2} \mathrm{O}_{4}$.
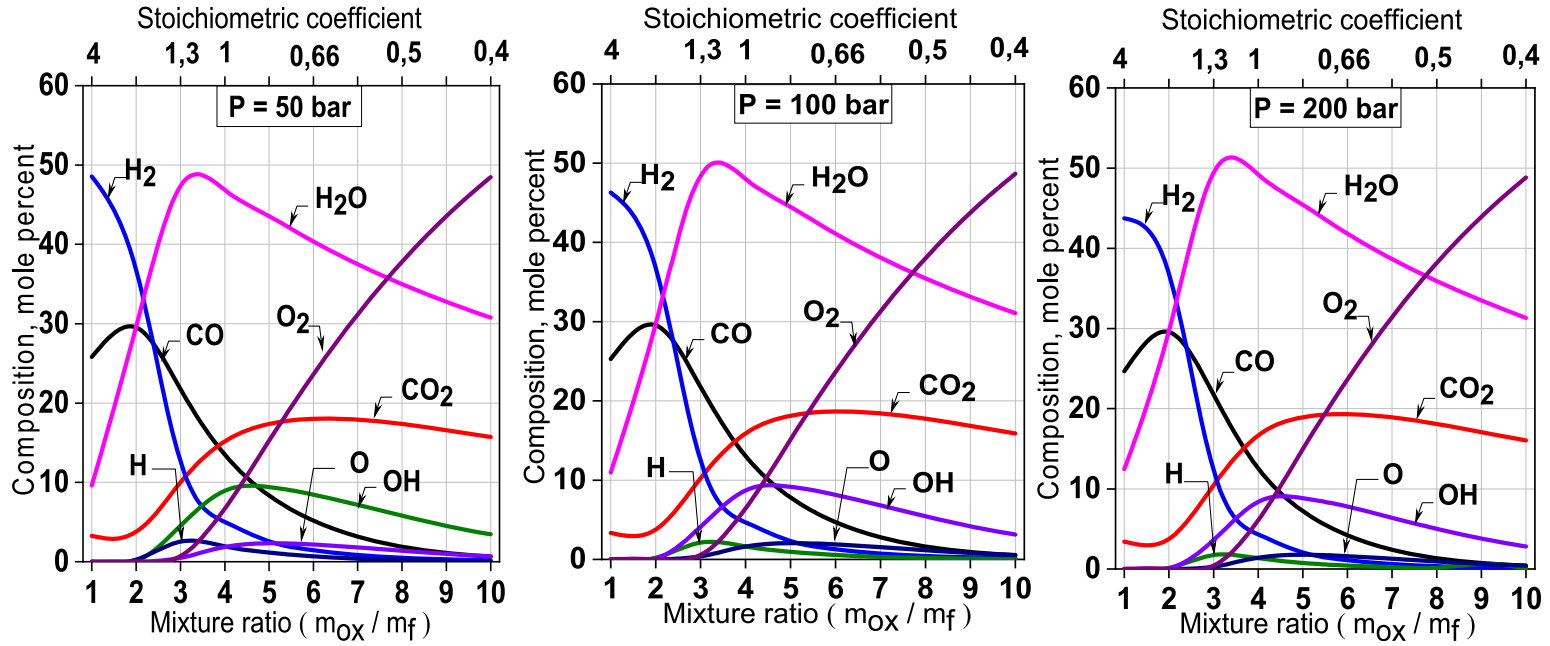

Fig. 21. Combustion products (\%) of the bipropellants $\mathrm{CH}_{4} / \mathrm{O}_{2}$. 
Table 1. Vulcain 2, Aestus, RD-170 and Raptor engine input data.

\begin{tabular}{lllll}
\hline & VULCAIN 2 & AESTUS & RD-170 & RAPTOR \\
\hline Fuel & $\mathrm{H}_{2}(\mathrm{~L})$ & $\mathrm{MMH}$ & $\mathrm{RP}-1$ & $\mathrm{CH}_{4}$ \\
Oxidizer & $\mathrm{O}_{2}(\mathrm{~L})$ & $\mathrm{N}_{2} \mathrm{O}_{4}$ & $\mathrm{O}_{2}(\mathrm{~L})$ & $\mathrm{O}_{2}(\mathrm{~L})$ \\
Mixture ratio & 6.1 & 2.05 & 2.6 & 3.8 \\
Chamber pressure (bar) & 115 & 10.0 & 245 & 250 \\
Nozzle area ratio & 58.5 & 84 & 33.5 & 40 \\
\hline
\end{tabular}
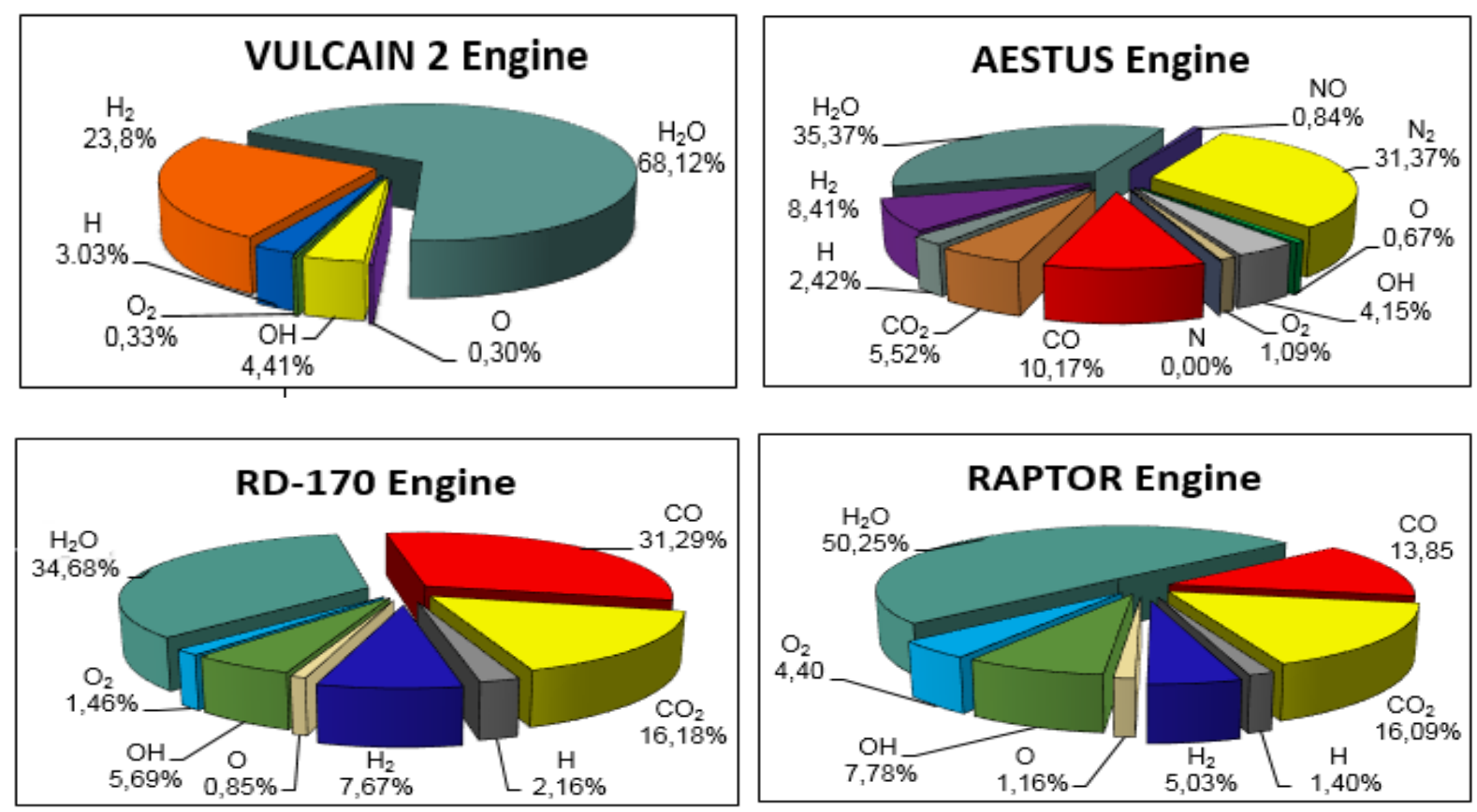

Fig. 22. Examples of combustion products (\%) of the various engines.

Table 2. Vulcain 2, Aestus, RD-170 and Raptor engine results.

\begin{tabular}{lllll}
\hline & VULCAIN 2 & AESTUS & RD-170 & RAPTOR \\
\hline Combustion Temperature $(\mathrm{K})$ & 3553.93 & 3176.49 & 3851.4 & 3741.8 \\
Molecular mass of the combustion products $(\mathrm{kg} / \mathrm{kmol})$ & 13.689 & 22.045 & 23.887 & 23.060 \\
Ejection speed $(\mathrm{m} / \mathrm{s})$ & 4000 & 2973 & 2834 & 2932 \\
Politropic parameter $(\gamma)$ & 1.1422 & 1.1331 & 1.1443 & 1.1330 \\
\hline
\end{tabular}

Table 3. Numerical design values for rockets engines.

\begin{tabular}{lllllllll}
\hline & $L$ & $Y_{E}$ & $\theta^{\circ}$ & $M^{*}$ & $C_{\text {Mass }}$ & $C_{F}$ & $M_{E}$ & $I_{S P}$ \\
\hline Vulcain 2 & 6.20 & 1.071 & 24.95 & 1.82 & 550.74 & 0.638 & 4.748 & 408.6 \\
Aestus & 4.21 & 0.653 & 25.58 & 1.86 & 881,09 & 0.618 & 5.390 & 300 \\
RD-170 & 10.66 & 2.002 & 22.75 & 1.76 & 290.61 & 0.596 & 4.266 & 312 \\
Raptor & 3.46 & 0.646 & 23.73 & 1.78 & 349.96 & 0.628 & 4.312 & 320 \\
\hline
\end{tabular}



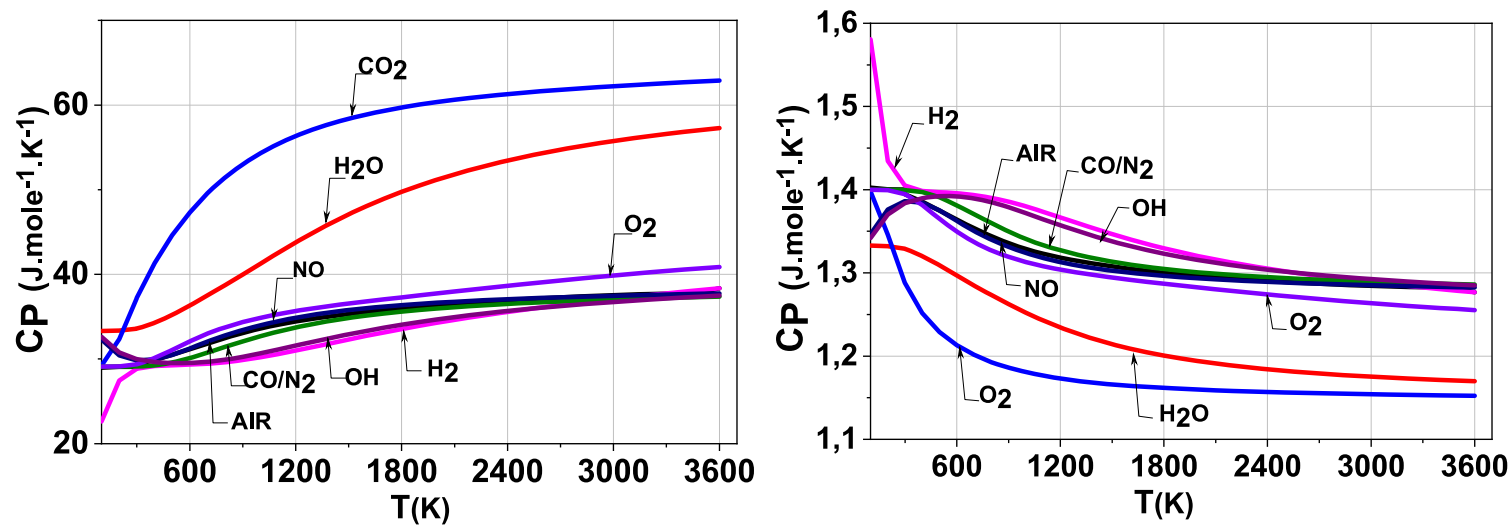

Fig. 23. Variation of the specific heat function $C_{P}$ and $\gamma$ as a function of the stagnation temperature $T_{0}$.
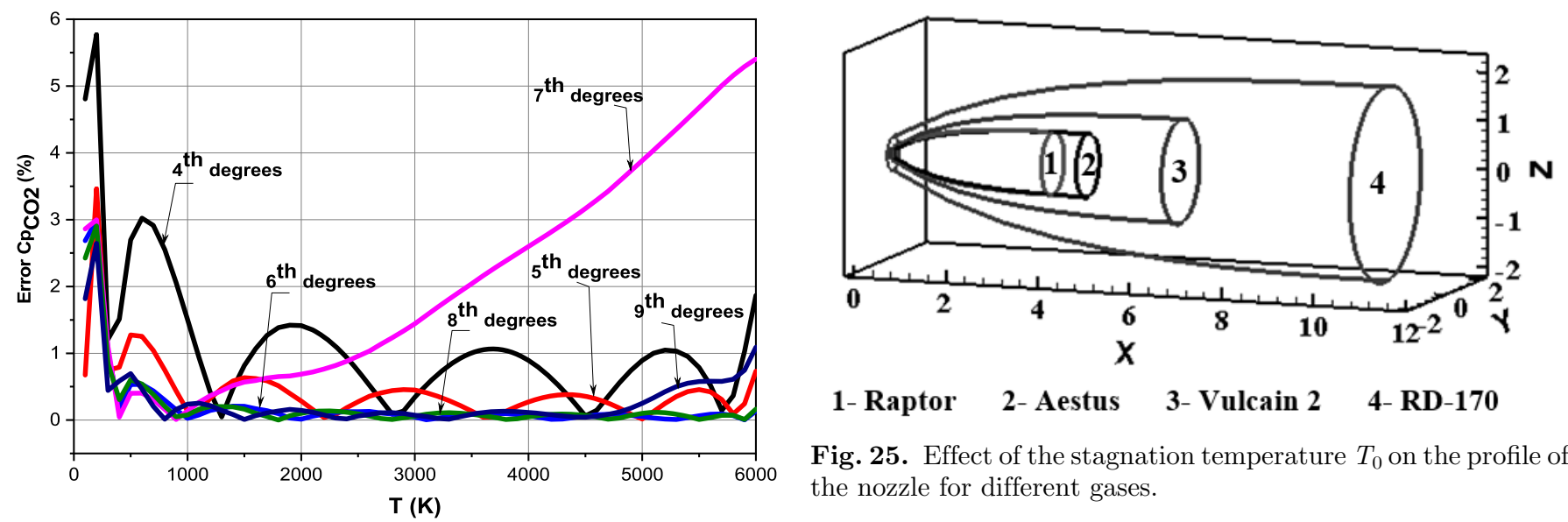

\section{1-Raptor 2-Aestus 3-Vulcain 2 4- RD-170}

Fig. 25. Effect of the stagnation temperature $T_{0}$ on the profile of the nozzle for different gases.

Fig. 24. Error calculation of $\mathrm{C}_{\mathrm{pCO} 2}$ for different interpolations polynomials.

Table 4. Numerical design values for truncated rockets engines.

\begin{tabular}{lccccccc}
\hline & $L$ & $Y_{E}$ & $C_{\text {Mass }}$ & $C_{F}$ & $\begin{array}{l}\text { Nozzle } \\
\text { area ratio }\end{array}$ & $\begin{array}{l}\text { Gain } \% \\
\left(C_{\text {Mass }}\right)\end{array}$ & $\begin{array}{l}\text { Loss } \% \\
\left(C_{\mathrm{F}}\right)\end{array}$ \\
\hline Vulcain 2 & 4.33 & 0.666 & 343.75 & 0.634 & 55.11 & 37.59 & 0.63 \\
Aestus & 3.03 & 0.428 & 568.58 & 0.615 & 79.96 & 35.47 & 0.49 \\
RD-170 & 7.42 & 1.222 & 181.47 & 0.591 & 31.51 & 37.56 & 0.84 \\
Raptor & 2.42 & 0.399 & 218.65 & 0.623 & 37.72 & 37.52 & 0.80 \\
\hline
\end{tabular}

\section{Effect of $T_{0}$ on the design parameters}

Figures 26-29 show the design parameters (length, coefficient of mass, nozzle area ration and vacuum specific impulse) of the nozzle of the following engines: Aestus, Vulcain 2, RD-170 and Raptor, for various values of the stagnation temperature $T_{0}$. From the numerical forms and results obtained, the effect of the combustor temperature $T_{0}$ on the design of axisymmetric $M L N$ nozzles has also been shown as presented in the reference studies $[12,15]$.

\section{Effect of $M_{E}$ on the design parameters}

Figures 30-33 show the variations in the design parameters of the $M L N$ nozzles of the four engines (Vulcain 2, Aestus, RD-170 and Raptor) as a function of $M_{E}$. It is clear that these parameters depend on $M_{E}$. For the length $(L)$, the coefficient mass $\left(C_{\text {Mass }}\right)$ as well as the nozzle area ration $\left(A_{E} / A^{*}\right)$, it can be noted that the curves of each figure representing the numerical results of each engine are almost identical up to $M_{E}=2.00$. But, beyond this value, they begin to be different as $M_{E}$ increases. It can be 


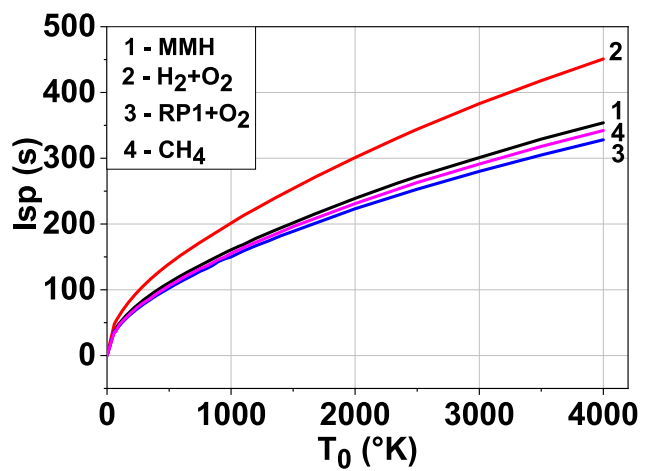

Fig. 26. Variation of $I_{s p}$ versus $T_{0}$.

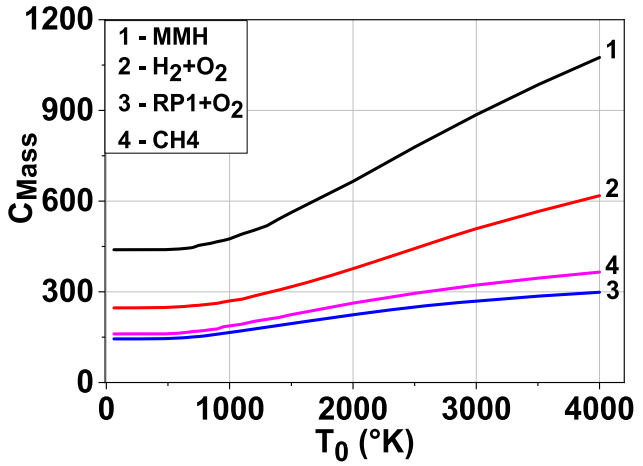

Fig. 27. Variation of $C_{\text {Mass }}$ versus $T_{0}$.

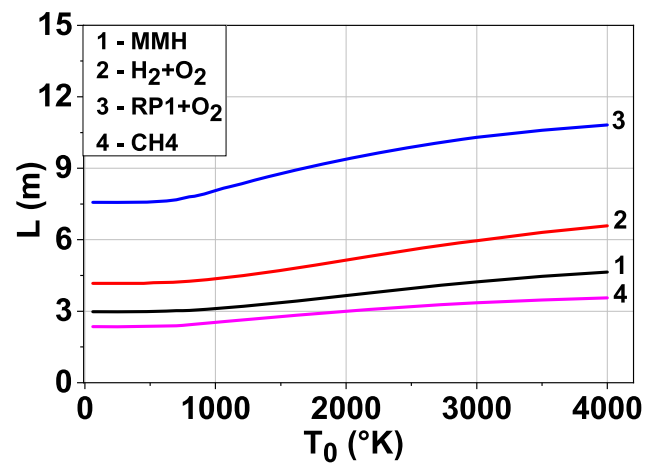

Fig. 28. Variation of $L$ versus $T_{0}$.

concluded that the nozzle, which corresponds to Aestus with its mass, its length and its vacuum specific impulse gives better results than those of others engines. On the other hand, we observe totally the opposite in the study of the vacuum specific impulse Isp, it is the Vulcain 2 engine which delivers more thrust compared to other engines.

\section{Effect of gas in the design of the nozzle}

In this section, we will study the effects of diatomic and triatomic products on the combustion (oxidant/fuel) combinations of liquid propellant engines in Figures 16-21, on the performance of $M L N$ axisymmetric

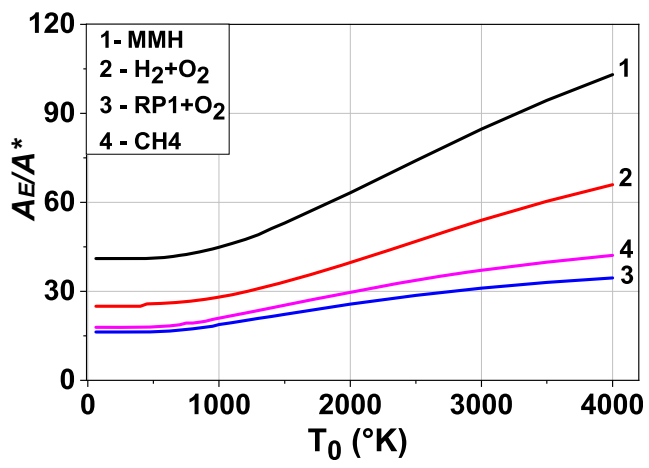

Fig. 29. Variation of $A_{E} / A^{*}$ versus $T_{0}$.

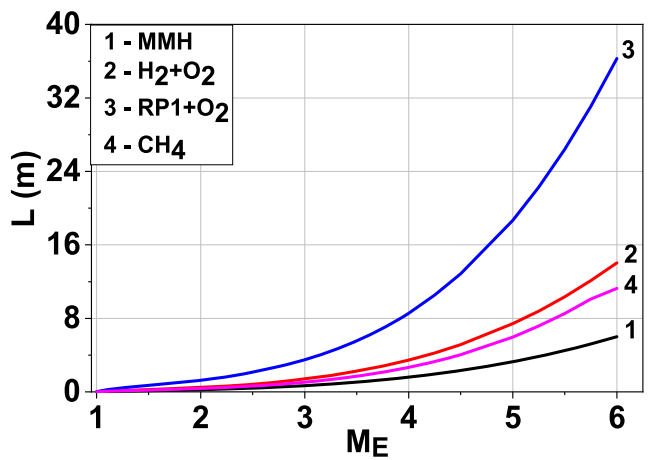

Fig. 30. Variation of $L$ versus $M_{E}$.

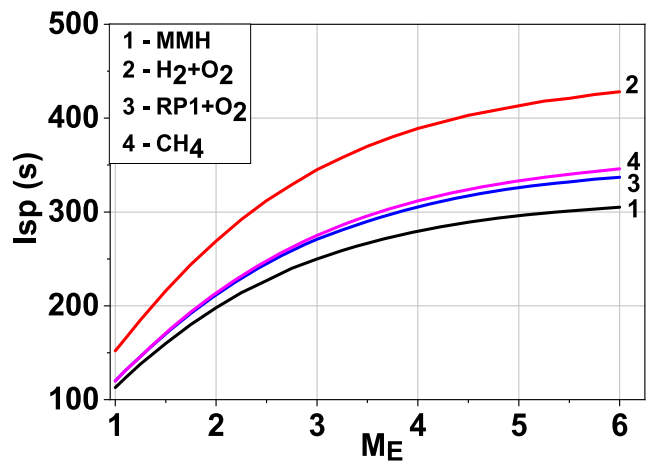

Fig. 31. Variation of $I_{s p}$ versus $M_{E}$.

supersonic nozzles. Table 5 shows a comparison with different diatomic gases on the design parameters. From the results obtained, the difference between values is negligible for the diatomic gases $\mathrm{H}_{2}, \mathrm{O}_{2}, \mathrm{OH}, \mathrm{CO}$ and $\mathrm{N}_{2}$. This difference is result of the gases molar mass influence on the nozzle velocity since the latter's have different molar masses. On the other hand, it is shown, therefore, that the results of the diatomic gas nozzles are almost identical with those of the air, which is also a $99 \%$ diatomic gas.

In order to illustrate the influence of the triatomic gases $\left(\mathrm{H}_{2} \mathrm{O} / \mathrm{CO}_{2}\right)$ combustion products in the design of the nozzles, we us equation (10) in the calculation code. Figure 34 shows this results for cases where $\lambda$ equal to $0 \%$, 


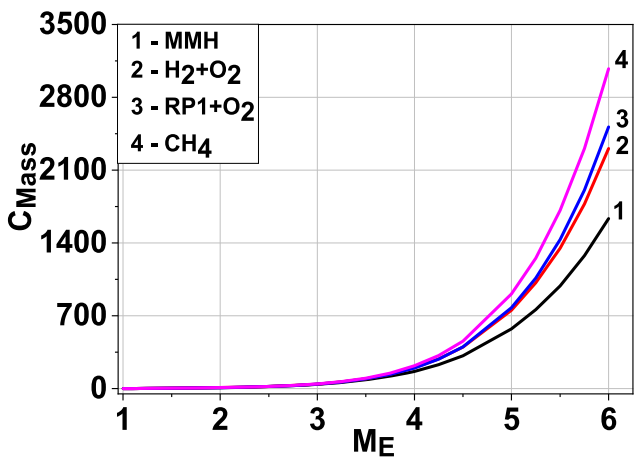

Fig. 32. Variation of $\mathrm{C}_{\text {Mass }}$ versus $M_{E}$.

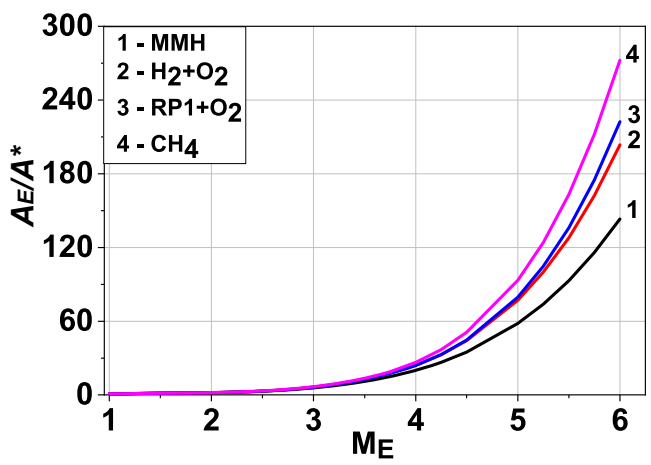

Fig. 33. Variation of $A_{E} / A^{*}$ versus $M_{E}$.

Table 5. Numerical design values of diatomic gas for $M_{E}=5.00$ and $T_{0}=3000 \mathrm{~K}$.

\begin{tabular}{llllllll}
\hline & $L / / y^{*}$ & $y_{E} / y^{*}$ & $\theta^{\circ}$ & $M^{*}$ & $C_{\text {Mass }}$ & $C_{F}$ & $A_{E} / A^{*}$ \\
\hline $\mathrm{Air}$ & 38.785 & 6.354 & 22.26 & 1.789 & 401.1 & 0.525 & 40.39 \\
$\mathrm{H}_{2}$ & 34.571 & 5.649 & 21.11 & 1.756 & 319.1 & 0.489 & 31.94 \\
$\mathrm{OH}$ & 35.481 & 5.802 & 21.40 & 1.764 & 336.4 & 0.499 & 33.70 \\
$\mathrm{O}_{2}$ & 41.067 & 6.737 & 22.84 & 1.802 & 449.9 & 0.544 & 45.45 \\
$\mathrm{CO} / \mathrm{N}_{2}$ & 38.202 & 6.256 & 22.10 & 1.787 & 389.1 & 0.521 & 39.15 \\
\hline
\end{tabular}
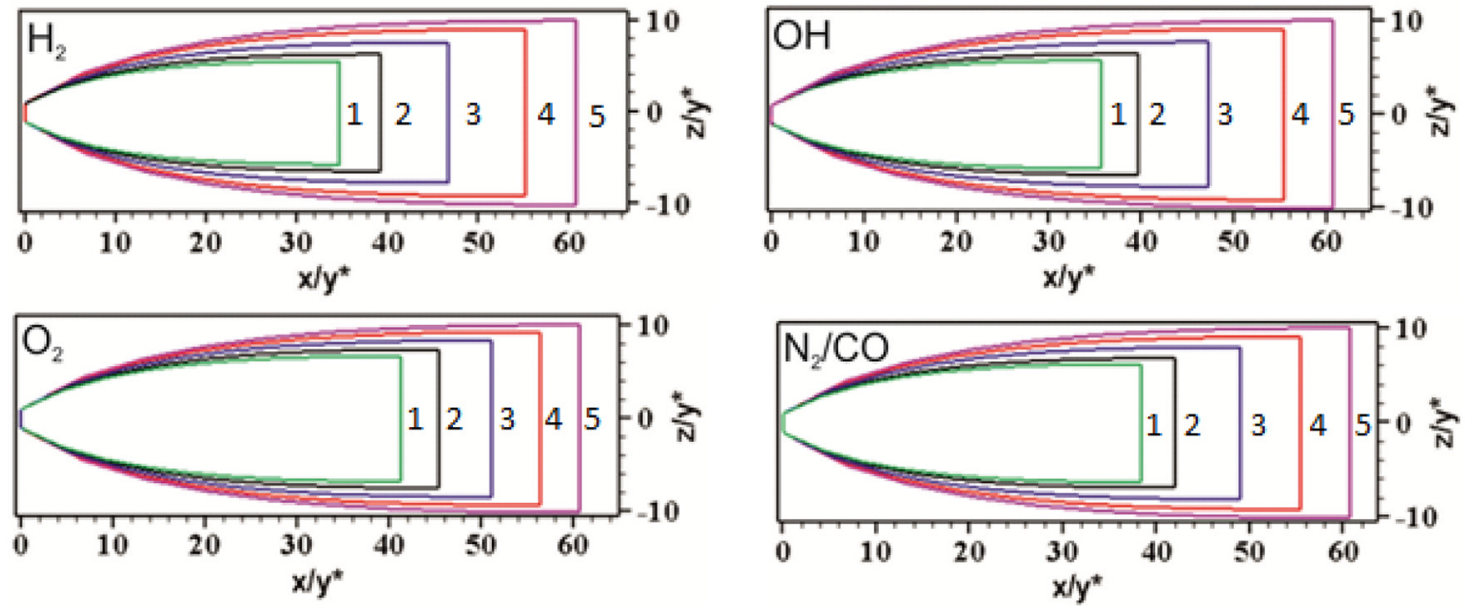

\begin{tabular}{llllll}
$1: 10 \%$ & $2: 20 \%$ & $3: 50 \%$ & $4: 80 \%$ & $5: 100 \%$ \\
\hline
\end{tabular}

Fig. 34. Influence of triatomic gas $\mathrm{H}_{2} \mathrm{O}$ with different gases.

$20 \%, 50 \%, 80 \%$ and $100 \%$.

$$
C p_{\text {melange }}(T)=(1-\lambda) C p_{\mathrm{Gas}_{1}}(T)+\lambda C p_{\mathrm{Gas}_{2}}(T) \quad \lambda \in[0,1] \text {. }
$$

From the numerical forms and results obtained in Figure 34, the increase and decrease in the percentage of diatomic gases $\left(\mathrm{H}_{2}, \mathrm{OH}, \mathrm{O}_{2}, \mathrm{NO}, \mathrm{N}_{2}\right.$ and $\left.\mathrm{CO}\right)$ have little effect on design (such as: length, exit radius, nozzle area ratio) and performance of supersonic nozzle (mass coefficient and thrust coefficient). However, the difference of the contours corresponding to $\mathrm{H}_{2} \mathrm{O}$ gas is very large and increases considerably the performances of axisymmetric minimum length nozzle, compared to that of diatomic gases. For example, the increase of $50 \%$ of $\mathrm{H}_{2} \mathrm{O}$, increases the nozzle design parameters (diatomic gas including air) in the order of $25 \%$. These errors are due to variations in the function $\gamma(T)$.

Table 6 presents the differences between the results of the increase in the percentage of triatomic $\mathrm{H}_{2} \mathrm{O}$ gas with other diatomic gases. Otherwise, the obtained results are 
Table 6. Numerical design values of Figure 34 for $M_{E} 5.00$ and $T_{0}=3000 \mathrm{~K}$.

\begin{tabular}{|c|c|c|c|c|c|c|c|c|}
\hline & & $L / / y^{*}$ & $y_{E} / y^{*}$ & $\theta^{\circ}$ & $M^{*}$ & $C_{\text {Mass }}$ & $C_{F}$ & $A_{E} / A^{*}$ \\
\hline $\mathrm{H}_{2} \mathrm{O}$ & & 60.532 & 10.073 & 27.42 & 1.871 & 984.4 & 0.708 & 101.48 \\
\hline \multirow[b]{2}{*}{$\mathrm{H}_{2}$} & $50 \%$ & 46.522 & 7.680 & 24.54 & 1.818 & 580 & 0.606 & 59.04 \\
\hline & $80 \%$ & 39.014 & 6.403 & 22.53 & 1.782 & 407.1 & 0.537 & 41.04 \\
\hline \multirow{3}{*}{$\mathrm{OH}$} & $50 \%$ & 47.081 & 7.775 & 24.65 & 1.821 & 593.5 & 0.610 & 60.47 \\
\hline & $80 \%$ & 39.581 & 6.498 & 22.66 & 1.787 & 418.4 & 0.541 & 42.23 \\
\hline & $50 \%$ & 50.870 & 8.418 & 25.45 & 1.837 & 692.9 & 0.637 & 70.87 \\
\hline $\mathrm{O}_{2}$ & $80 \%$ & 45.219 & 7.450 & 24.06 & 1.816 & 546.4 & 0.587 & 55.54 \\
\hline \multirow{2}{*}{$\mathrm{CO} / \mathrm{N}_{2}$} & $50 \%$ & 48.872 & 8.077 & 25.03 & 1.830 & 640.2 & 0.622 & 65.31 \\
\hline & $80 \%$ & 41.873 & 6.881 & 23.20 & 1.803 & 468.6 & 0.558 & 47.40 \\
\hline
\end{tabular}
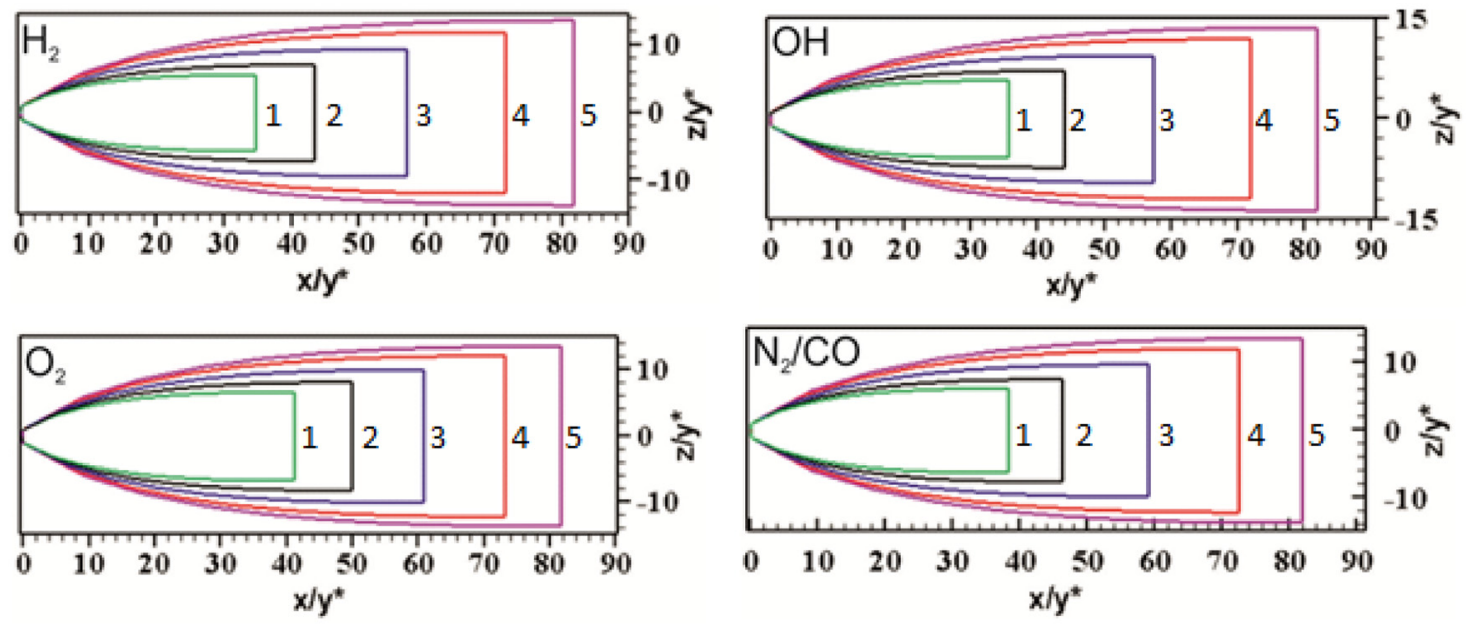

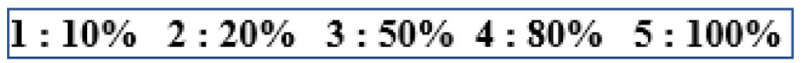

Fig. 35. Influence of triatomic gas $\mathrm{CO}_{2}$ with different gases.

compared to these of air gas [17]. This difference is very considerable. So, considering air for the design of supersonic nozzles is far from reality.

Figure 35 illustrates the influence of the presence of the triatomic gas $\mathrm{CO}_{2}$ on the contours of the supersonic nozzle for diatomic gases $\left(\mathrm{H}_{2}, \mathrm{OH}, \mathrm{O}_{2}, \mathrm{NO}, \mathrm{N}_{2}\right.$ and $\left.\mathrm{CO}\right)$. These profiles, calculated numerically by our calculation code, correspond to the case where the percentage of presence of the $\mathrm{CO}_{2}$ gas in the mixture is $0 \%, 20 \%, 50 \%$, $80 \%$ and $100 \%$. The comparison shows that the presence of $\mathrm{CO}_{2}$ gas in combustion species increases considerably the design parameters of supersonic minimum nozzle. We notice, these increases depend on the percentage of these gases in combustion (oxidizer/fuel).

Table 7 summarizes the various calculated nozzle parameters and their corresponding percentage presence of triatomic $\mathrm{CO}_{2}$ gases. For example, an increase of $50 \%$ in the $\mathrm{CO} 2$ content in a combustion causes an expansion of approximately $35 \%$ for the length and the exit radius. This evaluation becomes greater for the ratio of the exit sections which is of the order of $55 \%$. This configuration will therefore increase the weight of the nozzle.
In conclusion, the performance of a rocket engine propelled by a liquid bipropellant is maximum when the presence of $\mathrm{CO}_{2}$ in the combustion is maximum as seen in Figures 16-21. On the other hand, an increase of $\mathrm{H}_{2} \mathrm{O}$ automatically leads to an increase in its performances.

\section{Conclusion}

The present work concerns is to investigate numerically the effect of adding the gas (diatomic/triatomic) type on the design and performance of axisymmetric $M L N$ nozzles, as well as with the flow parameters study (pressure, mass, length, coefficients of mass and thrust) using the method of characteristics $(M O C)$ at high temperature. A FORTRAN language programme code has been developed for this purpose. The gases used in this study were calculated after a thermochemical of the combustion of liquid propellants (the most widely used in the space propulsion domain) of four spacecrafts: Ariane 5 (Vulcain 2), Ariane-5 upper stage engine (Aestus), Zenit first stage (RD-170) and Falcon 9 upper stage (Raptor). The combinations studied are: 
Table 7. Numerical design values of Figure 35 for $M_{E}=5.00$ and $T_{0}=3000 \mathrm{~K}$.

\begin{tabular}{|c|c|c|c|c|c|c|c|c|}
\hline & & $L / / y^{*}$ & $y_{E} / y^{*}$ & $\theta^{\circ}$ & $M^{*}$ & $C_{\text {Mass }}$ & $C_{F}$ & $A_{E} / A^{*}$ \\
\hline \multicolumn{2}{|l|}{$\mathrm{CO}_{2}$} & 81.526 & 13.66 & 30.37 & 1.933 & 1789 & 0.813 & 186.59 \\
\hline \multirow[b]{2}{*}{$\mathrm{H}_{2}$} & $50 \%$ & 56.817 & 9.426 & 26.53 & 1.863 & 864.9 & 0.673 & 88.89 \\
\hline & $80 \%$ & 43.244 & 7.117 & 23.59 & 1.805 & 499.5 & 0.572 & 50.66 \\
\hline \multirow{3}{*}{$\mathrm{OH}$} & $50 \%$ & 57.290 & 9.505 & 26.60 & 1.866 & 879.4 & 0.676 & 90.40 \\
\hline & $80 \%$ & 43.915 & 7.229 & 23.74 & 1.811 & 515.3 & 0.576 & 52.29 \\
\hline & $50 \%$ & 60.709 & 10.09 & 27.20 & 1.837 & 987.7 & 0.696 & 101.81 \\
\hline $\mathrm{O}_{2}$ & $80 \%$ & 49.789 & 8.225 & 25.07 & 1.836 & 662.9 & 0.621 & 67.70 \\
\hline \multirow{2}{*}{$\mathrm{CO} / \mathrm{N}_{2}$} & $50 \%$ & 58.904 & 9.779 & 26.87 & 1.873 & 929.9 & 0.685 & 95.70 \\
\hline & $80 \%$ & 46.186 & 7.610 & 24.21 & 1.825 & 569.7 & 0.591 & 57.95 \\
\hline
\end{tabular}

$\mathrm{H}_{2} / \mathrm{O}_{2}, \mathrm{RP}-1 / \mathrm{O}_{2}, \mathrm{MMH} / \mathrm{N}_{2} \mathrm{O}_{4}$ and $\mathrm{CH}_{4} / \mathrm{O}_{2}$. These gases are: $\mathrm{H}_{2} \mathrm{O}, \mathrm{CO}_{2}, \mathrm{H}_{2}, \mathrm{O}_{2}, \mathrm{OH}, \mathrm{CO}$ and $\mathrm{N}_{2}$. Once the profile mixture between gases previously mentioned (triatomic/ diatomic) is generated, an analysis of the evolution of the thermodynamic parameters (namely length, Mach number, mass and thrust coefficient) is conducted. The determination of the equilibrium composition, was solved numerically and it is function of mixture ratio by mass of oxidizer to fuel $(\mathrm{O} / \mathrm{F})$. Furthermore, spacecraft engine performance has also been calculated. These will have a maximum value at a wealth equal to 1 .

The effect of the stagnation temperature $T_{0}$ and the exit Mach number $M_{E}$ on the values of the nozzle design parameters and the numerical results obtained show that the difference between each engine is negligible are almost identical up to $M_{E}=2.00$.

The increase and decrease in the percentage of diatomic gases $\left(\mathrm{H}_{2}, \mathrm{OH}, \mathrm{O}_{2}, \mathrm{NO}, \mathrm{N}_{2}\right.$ and $\mathrm{CO}$ including air) have little effect on design (such as: length, exit radius, nozzle area ratio) and performance of supersonic nozzle (mass coefficient and thrust coefficient).

The difference of the contours corresponding to $\mathrm{H}_{2} \mathrm{O}$ gas is very large and increases considerably the performances of axisymmetric minimum length nozzle, compared to that of diatomic gases. The increase of $50 \%$ of $\mathrm{H}_{2} \mathrm{O}$, increases the nozzle design parameters in the order of $25 \%$.

The comparison shows that the presence of $\mathrm{CO}_{2}$ gas in combustion species increases considerably the design parameters of supersonic minimum nozzle. We notice, these increases depend on the percentage of these gases in combustion (oxidizer/fuel). For example, an increase of $50 \%$ in the $\mathrm{CO}_{2}$ content in a combustion causes an expansion of approximately $35 \%$ for the length and the exit radius. This evaluation becomes greater for the ratio of the exit sections which is of the order of $55 \%$. This configuration will therefore increase the weight of the nozzle.

The truncation method is applied in the $M L N$ nozzles to optimize the thrust/weight ratio. The related mass gain and $C_{F}$ loss depend on the position of the truncation section with respect to the exit section, the number of exit Mach number $M_{E}$ of the nozzle and the stagnation temperature $T_{0}$. For example, a $30 \%$ decrease in the length of the nozzle with the four engines application results in a gain of $37 \%$ of the mass coefficient and a loss of $0.6 \%$ of thrust coefficient.

\section{Nomenclature}

$A \quad$ Section area $\left(\mathrm{m}^{2}\right)$

a Coefficient of the specific heat at constant pressure function

$C^{-} \quad$ Left-running characteristic

$C^{+} \quad$ Right-running characteristic

$C_{F} \quad$ Thrust coefficient

$C_{\text {Mass }}$ Coefficient of the mass of the nozzle

$C_{P} \quad$ Specific heat at constant pressure $\left(\mathrm{J} \mathrm{kg}^{-1} \mathrm{~K}^{-1}\right)$

$H \quad$ Enthalpy (KJ)

$H T$ Abbreviation for high temperature

$I_{s p} \quad$ Vacuum specific impulse (s)

$L \quad$ Length of the nozzle $(\mathrm{m})$

M Mach number

Mass Mass through the nozzle normalized by $\left(\rho_{M} t_{M}\right)$ $\left(\mathrm{m}^{2}\right)$

$M L N$ Minimum Length Nozzle

$P \quad$ Pressure (bar)

$P G \quad$ abbreviation for perfect gas

$R \quad$ Thermodynamic constant of gas

$T \quad$ Temperature (K)

$x \quad$ Abscissa of a section in the nozzle

$y \quad$ Radius of a section in the nozzle

$\gamma \quad$ Specific heats ratio

$\rho \quad$ Density $\left(\mathrm{kg} / \mathrm{m}^{3}\right)$

$\theta \quad$ Flow angle deviation (rad)

$\mu \quad$ Mach angle

$v \quad$ Prandtl Meyer angle

$\varepsilon \quad$ Tolerance of calculation (desired precision)

$\xi \quad$ Downward Mach line

$\eta \quad$ Right-running Mach line

Indices

0 Stagnation condition (combustion chamber)

* Critical condition

S Supersonic section

$E$ Exit section

$M$ Material 


\section{References}

[1] G.P. Sutton, O. Biblarz, Rocket propulsion elements, 7th edn. (John Wiley \& Sons, New York, 2001)

[2] G.V.R. Rao, Exhaust nozzle contour for optimum thrust, Jet Propulsion 28, 377-382 (1958)

[3] J.M. Farley, C.E. Campbell, Performance of several method of characteristics exhaust nozzles, NASA TN D293, 1960

[4] B.M. Argrow, G. Emanuel, Comparison of minimum length nozzles, ASME J. Fluids Eng. 110, 283-288 (1988)

[5] B.M. Argrow, G. Emanuel, Computational analysis of the transonic flow field of two-dimensional minimum length nozzles, AIAA-1989-1822, in 20th Fluid Dynamics, Plasma Dynamics and Lasers Conference, Buffalo, NY, 1989, June $12-14$

[6] L.Z. Dumitrescu, Minimum length axisymmetric Laval nozzles, AIAA J. 13, 520-531 (1975)

[7] J.D. Anderson Jr., Modern compressible flow with historical perspective, 2nd edn. (McGraw-Hill Book Company, New York, USA, 1982)

[8] J.D. Anderson Jr., Fundamentals of aerodynamics, 2nd edn. (McGraw-Hill Book Company, New York, USA, 1988)

[9] T. Zebbiche, Z. Youbi, Effect of stagnation temperature on the supersonic flow parameters with application for air in nozzles, Aeronaut. J. 111, 31-40 (2007)

[10] M. White, A.I. Sayma, C.N. Markides, Supersonic flow of non-ideal fluids in nozzles: An application of similitude theory and lessons for ORC turbine design and flexible use considering system performance, J. Phys.: Conf. Ser. 821 (2017)

[11] A.P.S. Wheeler, J. Ong, The role of dense gas dynamics on organic Rankine cycle turbine performance, J. Eng. Gas Turb Power 135 (2013)
[12] A.C. Aldo, B.C. Argrow, Dense gas-flow in minimum length nozzles, J. Fluids Eng. 117, 270-276 (1995)

[13] M. Boun-jad, T. Zebbiche, A. Allali, High temperature gas effect on the Prandtl-Meyer function with application for supersonic nozzle design, Mech. Ind. 18, 219 (2017)

[14] M. Boun-jad, T. Zebbiche, A. Allali, High temperature gas effect on the supersonic axisymmetric Minimum Length Nozzle design, Int. J. Eng. Tech. Res. 7 (2017)

[15] T. Edwards, Liquid fuels and propellants for aerospace propulsion, 1903-2003, J. Propul. Power 19, 1089-1105 (2003)

[16] R. Amri, T. Rezoug, Numerical study of liquid propellants combustion for space applications, Acta Astronautica 69, 485-498 (2011)

[17] O. Abada, T. Zebbiche, A. Abdallah El-hirtsi, Three-dimensional supersonic minimum length nozzle design at high temperature for arbitrary exit cross section, Arab. J. Sci. Eng. 39, 7258-7879 (2014)

[18] T. Zebbiche, Rapid design method and new contours for a class of three dimensional supersonic nozzle of arbitrary exit cross section, Mech. Ind. 19, 403 (2018)

[19] T. Zebbiche, Stagnation temperature effect on the supersonic axisymmetric minimum length nozzle design with application for air, Adv. Space Res. 48, 1656-1675 (2011)

[20] D.D. Esch, W. Siripong, A.R. Pike, NASA technical report on the thermodynamic properties in polymonial form for carbon hydrogen nitrogen and oxygen systems, Louisiana, USA, 1970

[21] H. Kbab, M. Sellam, T. Hamitouche, S. Bergheul, L. Lagab, Design and performance evaluation of a dual bell nozzle, Acta Astron. 130, 52-59 (2017)

Cite this article as: O. Abada, A. Abada, A.A. El-Hirtsi, Effect of bipropellant combustion products on the rocket nozzle design, Mechanics \& Industry 21, 515 (2020) 